\title{
Modeling and Design of Single-Phase PV Inverter with MPPT Algorithm Applied to the Boost Converter Using Back-Stepping Control in Standalone Mode
}

\author{
Omar Diouri $\mathbb{D}^{1}{ }^{1}$ Najia Es-Sbai, ${ }^{1}$ Fatima Errahimi, ${ }^{1}$ Ahmed Gaga, ${ }^{1}$ and Chakib Alaoui ${ }^{2}$ \\ ${ }^{1}$ Electrical Department, Laboratory of Renewable Energies and Intelligent Systems (LERSI), Faculty of Sciences and Technology, \\ Sidi Mohamed Ben Abdellah University of Fez, Morocco \\ ${ }^{2}$ INSA, Euro-Méditerranée, EUROMED University, Fez, Morocco
}

Correspondence should be addressed to Omar Diouri; omar.diouri1@usmba.ac.ma

Received 3 March 2019; Revised 19 July 2019; Accepted 8 August 2019; Published 6 November 2019

Academic Editor: Huiqing Wen

Copyright (C) 2019 Omar Diouri et al. This is an open access article distributed under the Creative Commons Attribution License, which permits unrestricted use, distribution, and reproduction in any medium, provided the original work is properly cited.

\begin{abstract}
We propose a high-performance and robust control of a transformerless, single-phase PV inverter in the standalone mode. First, modeling and design of a DC-DC boost converter using a nonlinear back-stepping control was presented. The proposed converter uses a reference voltage that is generated by the Perturb and Observe (P\&O) algorithm in order to extract the maximum power point (MPP) by responding accurately to varying atmospheric conditions. Another goal for using the boost converter is to raise the voltage at the input of the inverter without using a transformer in this system, thus making the system more compact and less expensive. Secondly, the single-phase H-bridge inverter was controlled by using back-stepping control in order to eliminate the error between the output voltage of the inverter and the desired value, even if there is acute load variation at the output of the inverter. The stability of the boost converter and H-bridge inverter was validated by using Lyapunov's stability theory. Simulation results show that the proposed PV system with back-stepping controllers has a good extraction of the MPP with an efficiency of $99.93 \%$ and $1 \mathrm{~ms}$ of response time. In addition, the sinusoidal form of the output voltage of the inverter is fixed to $220 \mathrm{~V}$ and the total harmonic distortion of the output voltage was found to be less than $1 \%$.
\end{abstract}

\section{Introduction}

In recent years, several researches were focused on how to decrease the environmental pollution on Earth by using clean sources of energy such as solar, wind, hydro, biomass, and biogas [1]. These types of renewable energies are frequently applied to distributed generation (DG) [2]. In 2014, the world's electricity consumption amounted to approximately 20.7 trillion kilowatt-hours according to [3], having a net increase of 7,323 terawatt-hours since 1980. Moreover, in 2015, the World Bank estimated that $22.69 \%$ of the world's rural population were not able to access electricity, since the source of power is often located geographically far from the consumers, requiring expensive distribution of this electricity by using transmission lines. According to the World Bank, $8.26 \%$ of the worldwide-transmitted power in 2014 is lost due to losses associated with transmission lines. One way to circumvent these issues is to use distributed power generation units based on photovoltaic systems.

Currently, there are two types of PV systems: gridconnected and standalone [4]. In order to inject the DC energy available at the output of photovoltaics into the grid, it is necessary to use converters as an interface $[5,6]$. This system is known as the grid-connected PV system. On the other hand, a standalone PV system consists of the transformation of photovoltaic electricity to AC loads available at the consumer's sites. Power converters are necessary in order to make interconnection between solar PV modules and AC loads. These power converters should accomplish two principal functions: first, to ensure that the PV array always generates the maximum power regardless of the variations of the atmospheric and load conditions. This is referred to as the maximum power point tracker or simply MPPT. The second function is the conversion of the continuous voltage 
generated by the PV array into the alternative voltage to be used by the AC loads. This AC output voltage should have the same performance and parameters as the grid, namely, having a stable frequency, amplitude, and sinusoidal form. In $[7,8]$, an overview of many topologies was presented to attain these purposes.

In this paper, a converter with a two-stage topology is used. It consists of a boost converter and an H-bridge inverter. The main objective of the first stage (boost converter) is allowing the $\mathrm{PV}$ array to generate the maximum power using the MPPT technique [9]. There are several algorithms used to track the MPP effectively; the authors of [10] showed that the back-stepping algorithm gives good results. Several publications explore two broad categories of MPPT techniques: indirect MPP tracking like the fractional open circuit voltage method [11], direct MPP tracking like the incremental conductance $[12,13]$, or the Perturb and Observe (P\&O) method that is implemented in this work. The authors of [12] achieved a response time of $7 \mathrm{~ms}$ in order to track the suitable value of the power using the proposed modified incremental conductance, and an efficiency of $97.53 \%$. In [14], the rise time of the back-stepping control of MPPT and the integral back-stepping were $2.42 \mathrm{~ms}$ and $2.17 \mathrm{~ms}$, respectively. In [10], efficiencies of $96 \%, 96.5 \%$, $98.2 \%$, and $99.1 \%$ were obtained by using $\mathrm{P} \& \mathrm{O}$ algorithm, PI, neuro-fuzzy, and back-stepping, respectively. Our main objectives are to achieve a lower response time and higher efficiency in the MPPT stage. The $\mathrm{P} \& \mathrm{O}$ algorithm takes advantage of the fact that the $\mathrm{P}-\mathrm{V}$ curve has a decreasing nature to the right of the MPP and an increasing nature to the left of the MPP. The drawback of this algorithm is that the operating point is never stable and steady at the MPP. It is always oscillating around in the MPP region. This could be reduced using very small perturbation steps around the MPP. Another shortcoming is that there is no regulation of the output voltage of the DC-DC converter. This issue should be taken into consideration as the authors mentioned in [15]. By using the back-stepping control with the MPPT block, we can generate the reference voltage to be tracked by the controller. In addition, the control for boost converter forces the PV array to provide the same voltage as the MPPT block. For nonlinear systems, the use of a suitable controller is necessary to stabilize the system in the point considered. Therefore, to test the robustness of this controller, we have forced this system to high changes of solar irradiance in a short time and the results show that our proposed system tracks perfectly the reference power using back-stepping.

The second stage of the proposed solution consists of an inverter. In order to assure an efficient use of the DG units, especially designed inverters play the role of energy conversion and adaptation between the sources and the loads [16]. The conversion principle in these inverters is the use of a pulse width modulation (PWM) technique to offer a stable sinusoidal output voltage of $220 \mathrm{~V}$ AC to the load. Several inverters use power electronic switches such as MOSFET or IGBT in the output stage. The PWM technique makes these inverters suitable for all types of electrical appliances [16]. However, these inverters must have a low total harmonic distortion (THD), a fast transient response, and a high effi- ciency. Much attention has been paid to regulation of the PWM inverter in order to ensure a sinusoidal waveform voltage with low THD, unchangeable frequency, and fast dynamic response under different types of loads [17]. The most known methods of regulation are the proportionalintegral-derivative (PID) control [18], sliding-mode control [19], linear control [20], Lyapunov control [21], linear resonant control [22], and passivity-based control [23]. Kalantar Zadeh et al. presented in [24] a comparison between three types of controllers: sliding mode, back-stepping, and fuzzy logic. As a conclusion, the back-stepping was found to be the best controller which provides a higher performance. Kolbasi and Seker [25] proposed a nonlinear controller for inverters by using a robust back-stepping. However, having more than two gains makes the controller harder to control.

The objective of this study is to achieve a highperformance inverter having a fast dynamic response for quick reference tracking and a low THD for a purely sinusoidal voltage and that is more adaptive to different types of loads in the standalone mode. In order to reach these goals, we propose an inverter composed of two bridges of electronic switches concatenated with an LC filter circuit at the output. Our contributions in this stage of inverter is the regulation of the output voltage in different load values and in different values of solar irradiance with low THD and low response time. Our system is robust, since in the case of sudden change in weather conditions, such as a variation in temperature, sun irradiation, or both will cause the controller to quickly follow this variation. It is also robust in terms of regulation of the voltage since it maintains $220 \mathrm{~V}$ and a stable $50 \mathrm{~Hz}$ for any value of a varying load.

The back-stepping control has attracted the attention of many researchers, thanks to its capability to stabilize nonlinear dynamical systems. To design these dynamical systems, an analysis of the stability is necessary. For nonlinear systems, it is more complicated to verify the stability of equilibrium than linear dynamical systems. For that, the Lyapunov function is used to regulate the stability [26]. In general, the major step to the use of the Lyapunov theory is in constructing a suitable Lyapunov function. Therefore, there is no specific technique for building Lyapunov functions for ordinary differential equations, and the construction of Lyapunov functions is known in numerous cases. One of the methods of designing nonlinear controllers is based on Aleksandr Lyapunov's theory of stability of dynamical systems (Lyapunov, 1892) [27, 28]. Typically, the goal of the design is to find a negative function of the derivative of the Lyapunov candidate function. However, this task is rather complex for a large number of systems. Back-stepping is a design method developed by several authors including Petar V. Kokotovic (see [27]) and applied to certain classes of systems, which normalizes the design of the controller into a series of predefined steps. This strategy makes it possible to build progressively the expression of the command that can stabilize the system. The remainder of this paper is organized as follows: Section 2 talks about the overall description of the proposed singlephase PV inverter in the standalone mode. In Section 3, the dynamic model and back-stepping control design of both converters, the boost and the H-bridge, with a filter is 


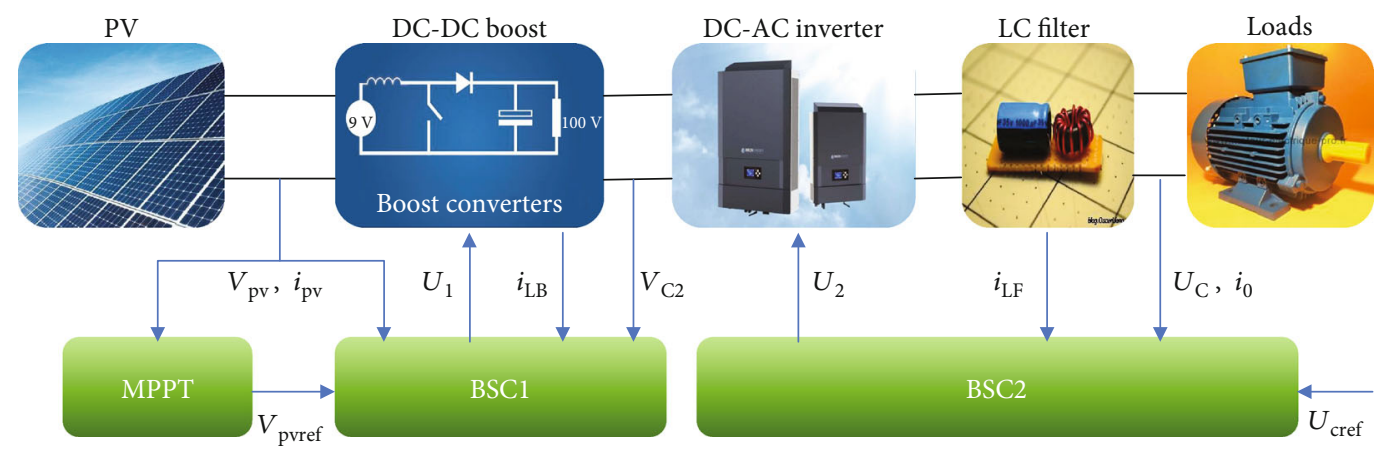

FIGURE 1: Block diagram of the proposed PV inverter system.

TABle 1: Parameters of the PV array.

\begin{tabular}{|c|c|c|}
\hline & Typical electrical characteristics & Value \\
\hline \multirow{8}{*}{ Module data } & Maximum power per module $\left(P_{\max }\right)$ & $244.62 \mathrm{~W}$ \\
\hline & Cells per module $\left(N_{\text {cell }}\right)$ & 60 \\
\hline & Open circuit voltage $\left(V_{o c}\right)$ & $37.2 \mathrm{~V}$ \\
\hline & Short circuit current $\left(I_{s c}\right)$ & $8.62 \mathrm{~A}$ \\
\hline & Voltage at maximum power point $\left(V_{m p p}\right)$ & $30.2 \mathrm{~V}$ \\
\hline & Current at maximum power point $\left(I_{m p p}\right)$ & $8.1 \mathrm{~A}$ \\
\hline & Temperature coefficient of $V_{o c}$ & $-0.36901 \% /{ }^{\circ} \mathrm{C}$ \\
\hline & Temperature coefficient of $I_{s c}$ & $0.086995 \% /{ }^{\circ} \mathrm{C}$ \\
\hline \multirow{5}{*}{ Array data } & Parallel strings & 1 \\
\hline & Series-connected modules per string & 4 \\
\hline & Maximum power of $\mathrm{PV}$ array & $978 \mathrm{~W}$ \\
\hline & Voltage at maximum power point of $\mathrm{PV}$ array & $120.8 \mathrm{~V}$ \\
\hline & Current at maximum power point of PV array & $8.1 \mathrm{~A}$ \\
\hline
\end{tabular}

presented. Finally, testing and simulation of the proposed system are shown by simulation results in Section 4. This paper ends with a conclusion.

\section{System's Description}

Figure 1 shows the block diagram of the proposed system. It includes two power electronic converters between the PV array and the AC loads. Each converter is controlled by a back-stepping system, having the role of providing the maximum power to the loads and ensuring a good conversion from DC to AC power. The first converter is a boost DC$\mathrm{DC}$ that is used to track the maximum electrical energy generated by the PV array, for different values of irradiance and temperature, using a basic MPPT algorithm type Perturb and Observe $(\mathrm{P} \& \mathrm{O})$. It generates the reference voltage to the back-stepping block in order to force the PV array to provide this voltage. The second converter is an $\mathrm{H}$-bridge inverter with LC filter having the role of converting continuous to alternative voltage with minimum harmonic distortion and good stability in terms of amplitude and frequency in different values of resistive loads.
2.1. PV Array and P\&O Algorithm. Photovoltaic energy is based on the conversion photons into electricity using semiconductor materials. Several solar cells constitute the photovoltaic generators; this solar cell is the basic element that can provide a few watts only. Therefore, a photovoltaic system uses solar panels which is an interconnection of several solar cells in parallel and in series in order to increase the current and the voltage, respectively. Moreover, to obtain larger values of power for large electrical installations, the association of several solar panels in parallel and/or in series is necessary and this association is referred to as a PV array. In this work, the solar panel considered is the monocrystalline $245 \mathrm{~W}$ and the total power of the PV array is $978 \mathrm{~W}$. The electrical characteristics of both the solar module and the PV array are listed in Table 1. The I-V and P-V curves associated with the PV array used for different values of solar irradiance and fixed temperature are shown in Figures 2 and 3.

The PV array generates different values of power depending on specific atmospheric conditions in terms of solar irradiance and temperature. However, there is one point of power that is considered as the maximum power point (MPP). There is one MPP for each curve, considering 


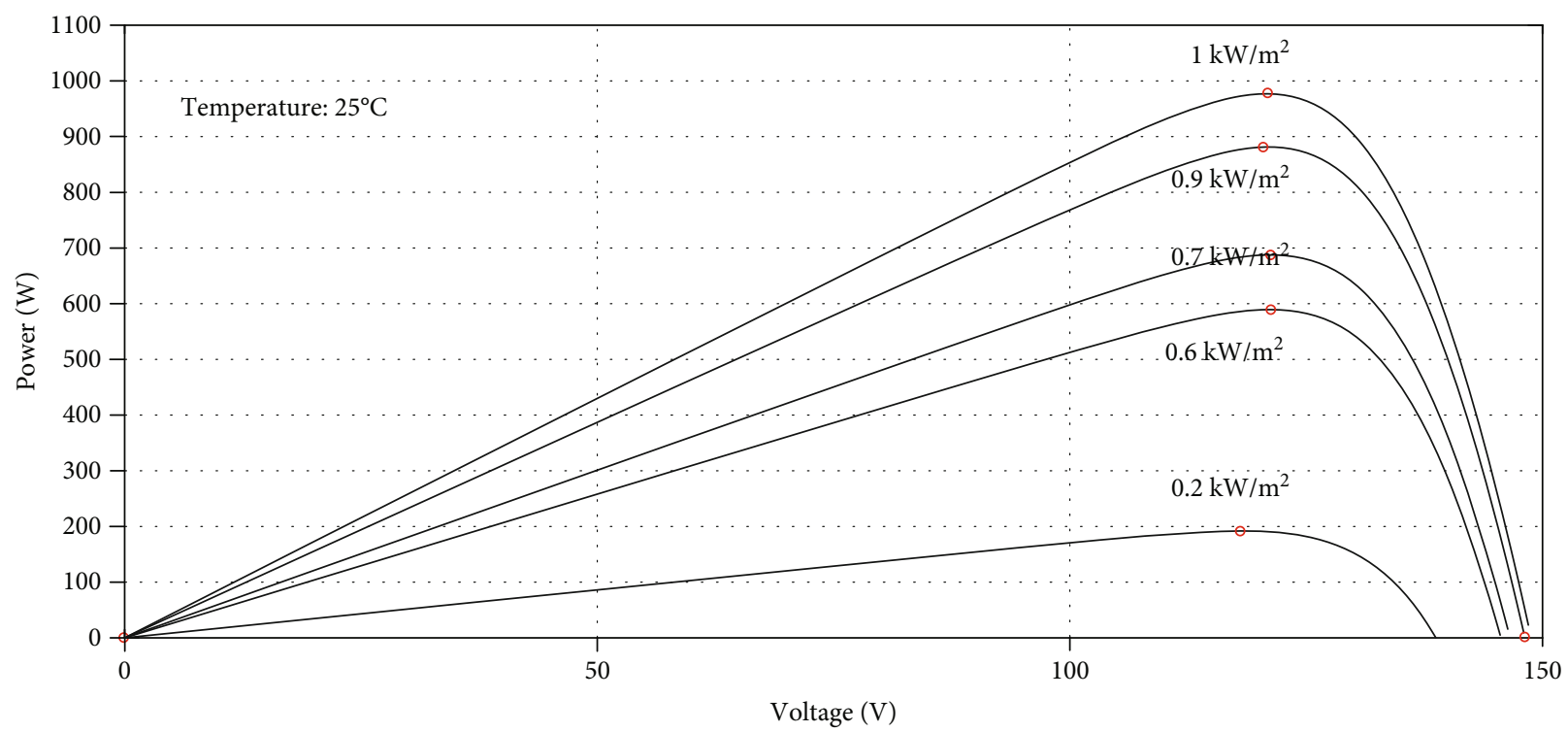

FIgURE 2: P-V curves of a PV array with different values of sun irradiance.

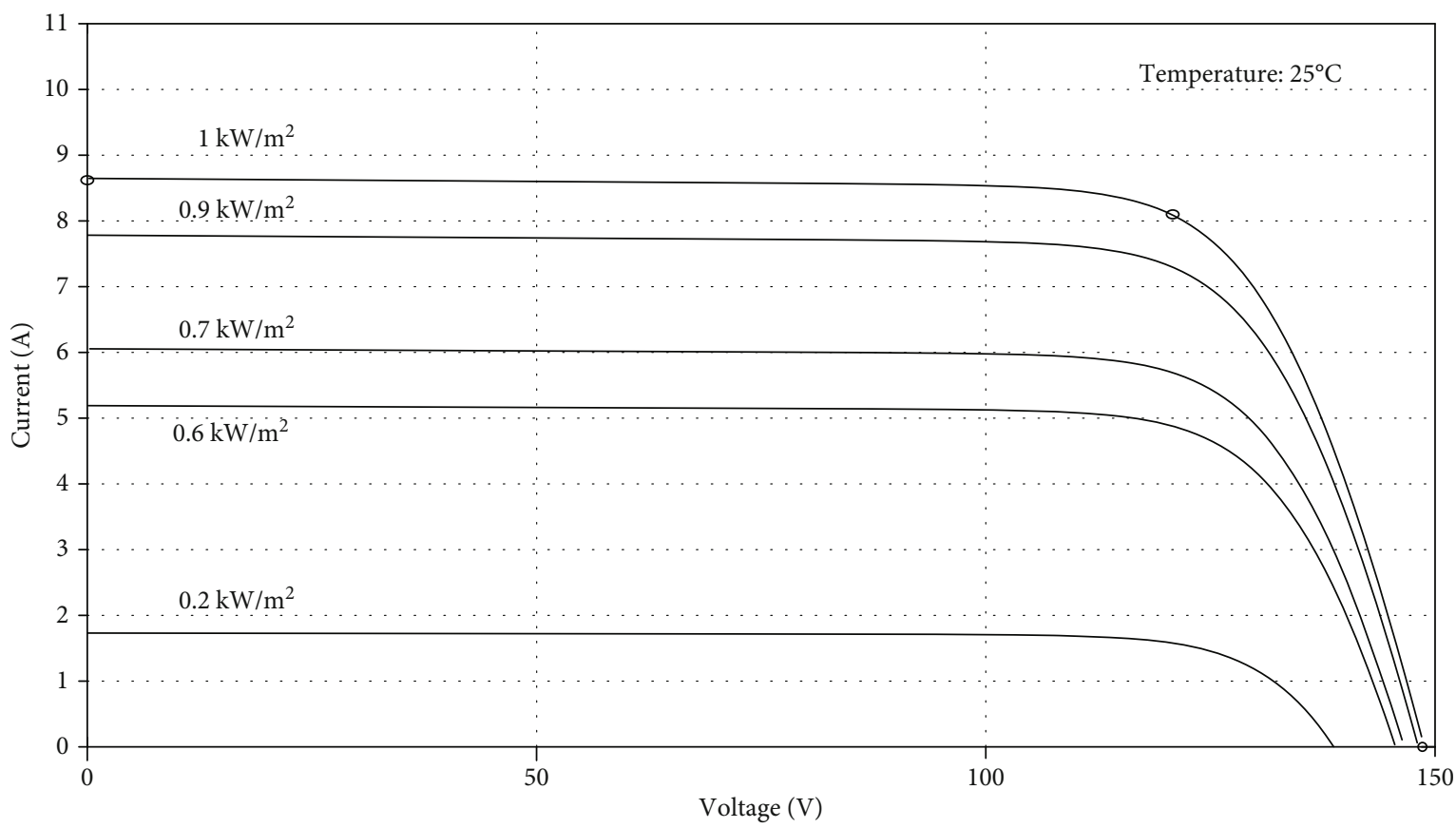

FIGURE 3: I-V curves of a PV array for different values of sun irradiance.

that the shading is negligible. The PV array should generate the maximum power using a specific algorithm to track this maximum which is commonly called the maximum power point tracking (MPPT). In this work, the $\mathrm{P} \& \mathrm{O}$ algorithm is applied to the PV array voltage, which would translate to an increase or decrease in power as shown in Figure 4. If a rise in voltage leads to a rise in power, this means that the operating point is the left of the MPP, and hence, further voltage perturbation is required towards the right to reach the MPP. Conversely, if a rise in voltage leads to a diminution in power, this means that the present operating point is to the right of the MPP, and hence, further voltage perturbation is required towards the left to reach the MPP. In this way, the algorithm converges towards the MPP after several perturbations.

2.2. Boost Converter. The second block after the PV array is a basic DC-DC converter of type boost that steps up the voltage from low input voltage, coming from the PV array, into high output voltage, going to the input of the inverter. The input of the boost converter is connected to the PV array in order to achieve the MPP in different atmospheric 


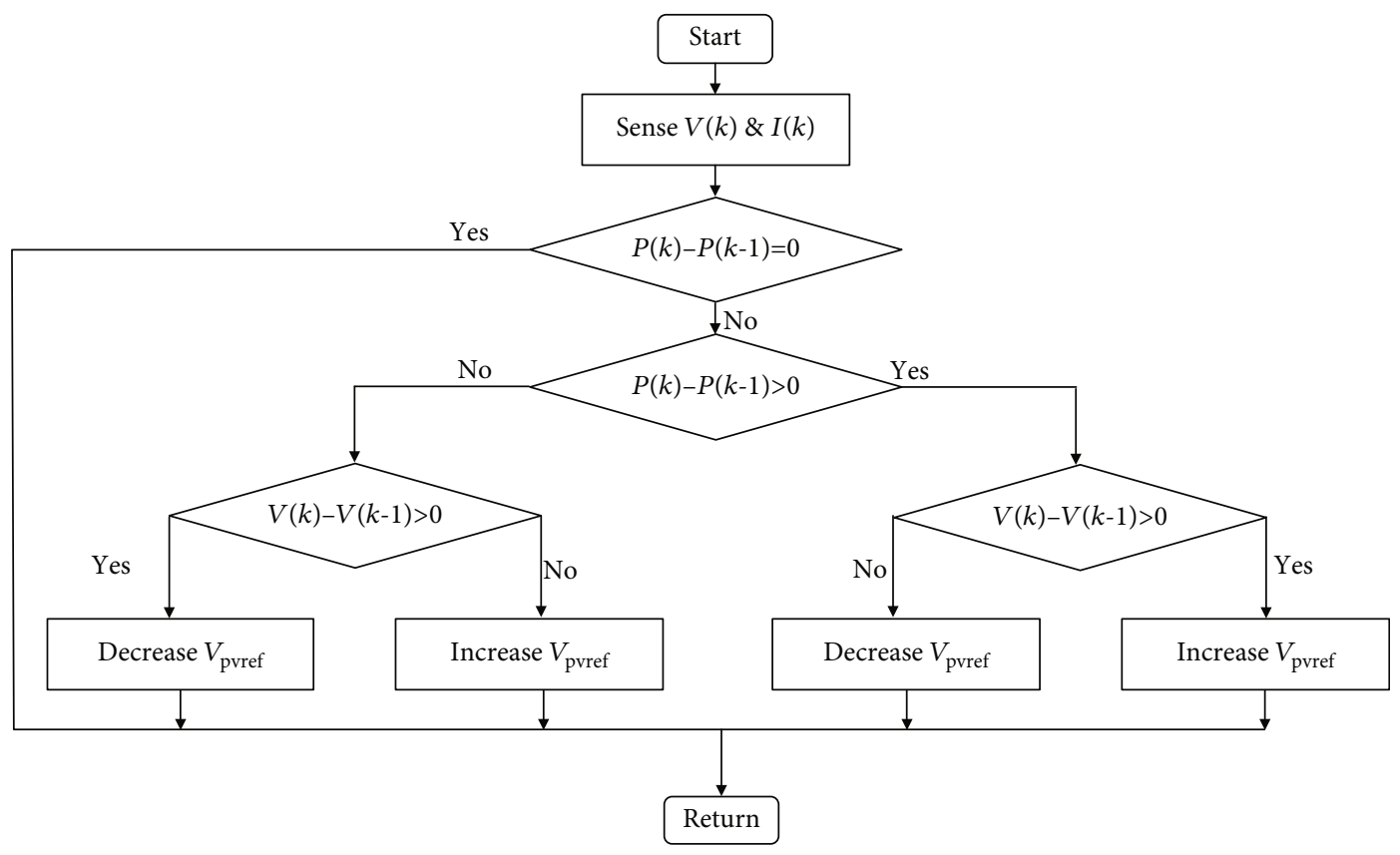

Figure 4: Flowchart of the P\&O algorithm.

conditions. Its output is connected to an $\mathrm{H}$-bridge inverter in order to obtain a higher voltage that can be supplied to the AC load without using a transformer. Figure 5 represents the synoptic block of the DC-DC converter with its controller. It is made with a back-stepping module to track the PV reference voltage generated by the MPPT block as defined in the previous section. This controller can generate a suitable duty cycle for controlling a power transistor of the boost converter using a PWM generator.

2.3. H-Bridge Inverter. A PWM inverter, cascaded with an LC filter in the standalone mode with back-stepping controller, is modeled in Figure 6. This inverter system is composed of two essential parts: the electrical power part and the control unit of this system. The electrical power part is composed of

(i) an $\mathrm{H}$-bridge converter which is typically composed of four electrical MOSFET transistors

(ii) an LC Filter that is necessary to obtain a sinusoidal waveform with an appropriate frequency and having a minimum distortion of the voltage at terminal loads

(iii) resistive loads, which represent the final consumer of this electricity

The second part of the system is the back-stepping controller who plays a significant role to achieve a high performance of the inverter in the standalone mode. It regulates the output voltage at terminal loads by using the control law of equation (43) developed in Section 3 of this manuscript.

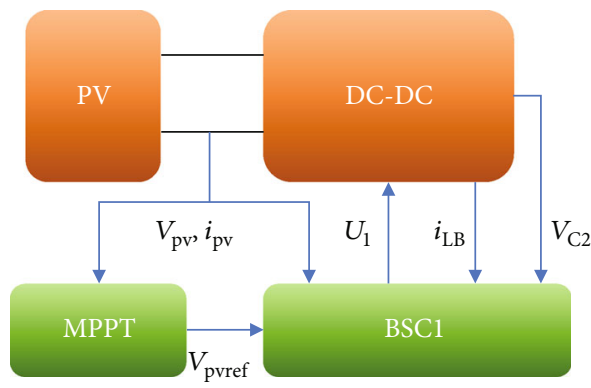

Figure 5: Block diagram of the first stage (boost converter).

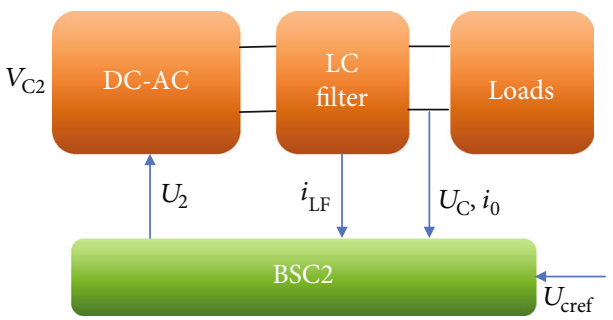

FiguRE 6: Block diagram of the second stage (H-bridge inverter).

\section{Dynamic Model and Back-Stepping Control Design}

3.1. Boost Converter. The basic schematic of the boost converter studied is depicted in Figure 7.

$i_{\mathrm{pv}}$ and $V_{\mathrm{pv}}$ are the photovoltaic current and the photovoltaic voltage generated by the $\mathrm{PV}$ array, respectively. $V_{\mathrm{pv}}$ is the parameter that should be regulated to achieve the MPP. $i_{\mathrm{LB}}$ and $V_{\mathrm{C} 2}$ are the current in the inductor $L_{B}$ and 


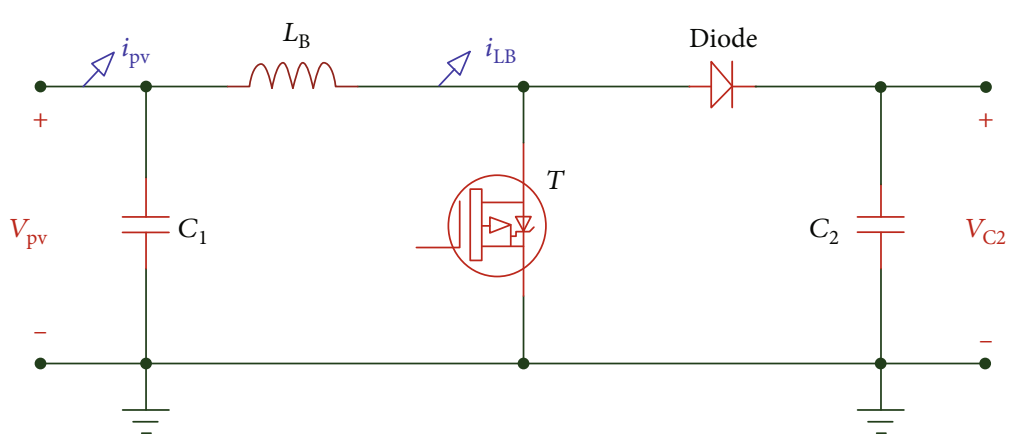

FIgURE 7: Basic schematic of the boost converter.

the output voltage of the boost converter, respectively. The switching frequency applied in the power electronic transistor has the value of $20 \mathrm{kHz}$. Applying the Kirchhoff theorem on the schematic of the boost as shown in Figure 7, (1) and (2) represent the dynamic model of the boost:

$$
\begin{aligned}
C_{1} \frac{d V_{\mathrm{pv}}}{d t} & =i_{\mathrm{pv}}-i_{\mathrm{LB}}, \\
L_{B} \frac{d i_{\mathrm{LB}}}{d t} & =V_{\mathrm{pv}}-\left(1-u_{1}\right) V_{\mathrm{C} 2} .
\end{aligned}
$$

By choosing the voltage $V_{\mathrm{pv}}$ as the system state and the control parameter $u_{1}$ as the signal control of the boost converter, (1) and (2) can be rearranged as follows:

$$
\begin{aligned}
& C_{1} \dot{x}_{1}=i_{\mathrm{pv}}-x_{2}, \\
& L_{B} \dot{x}_{2}=x_{1}-\left(1-u_{1}\right) V_{\mathrm{C} 2},
\end{aligned}
$$

where $x$ is the state vector of the second-order system. $x_{1}$ and $x_{2}$ are the average value of $V_{\mathrm{pv}}$ and $i_{\mathrm{LB}}$, respectively. $u_{1}$ is the control law.

$$
\begin{aligned}
& \dot{x}_{1}=\frac{1}{C_{1}} i_{\mathrm{pv}}-\frac{1}{C_{1}} x_{2}, \\
& \dot{x}_{2}=\frac{1}{L_{B}} x_{1}-\frac{\left(1-u_{1}\right)}{L_{B}} V_{\mathrm{C} 2} .
\end{aligned}
$$

The goal is to track the photovoltaic reference voltage in order to produce the maximum power by the PV array using a back-stepping control. The control law is generated based on the stability theory of the Lyapunov dynamic systems. Therefore, $e_{1}$ is the error and it is defined as

$$
\begin{aligned}
& e_{1}=x_{1}-V_{\mathrm{pvref}}, \\
& \dot{e}_{1}=\dot{x}_{1}-\dot{V}_{\mathrm{pvref}}=\frac{1}{C_{1}} i_{\mathrm{pv}}-\frac{1}{C_{1}} x_{2}-\dot{V}_{\mathrm{pvref}} .
\end{aligned}
$$

The first Lyapunov function $V_{1}$ is defined as

$$
V_{1}=\frac{1}{2} e_{1}^{2}
$$

so that its derivative is

$$
\dot{V}_{1}=e_{1} \dot{e}_{1}=e_{1}\left(\frac{1}{C_{1}} i_{\mathrm{pv}}-\frac{1}{C_{1}} x_{2}-\dot{V}_{\mathrm{pvref}}\right) .
$$

To get $\dot{V}_{1}=-k_{1} e_{1}^{2}<0$, it is necessary to have equation (8), where $k_{1}$ is a positive constant:

$$
\frac{1}{C_{1}} i_{\mathrm{pv}}-\frac{1}{C_{1}} x_{2}-\dot{V}_{\mathrm{pvref}}=-k_{1} e_{1}
$$

The virtual control of the system is $x_{2}^{*}$ that is equal to

$$
x_{2}^{*}=i_{\mathrm{pv}}+C_{1} k_{1} e_{1}-C_{1} \dot{V}_{\mathrm{pvref}}
$$

where the second error between the second state variable $x_{2}$ and its desired value $x_{2}^{*}$ is defined as follows:

$$
\begin{aligned}
& e_{2}=x_{2}-x_{2}^{*}, \\
& x_{2}=x_{2}^{*}+e_{2} .
\end{aligned}
$$

From the derivative of $V_{1}$ in (7), the expression of derivative of error $e_{1}$ can be written as

$$
\begin{aligned}
\dot{e}_{1} & =\frac{1}{C_{1}} i_{\mathrm{pv}}-\frac{1}{C_{1}}\left(x_{2}^{*}+e_{2}\right)-\dot{V}_{\mathrm{pvref}} \\
& =\frac{1}{C_{1}} i_{\mathrm{pv}}-\frac{1}{C_{1}} x_{2}^{*}-\frac{1}{C_{1}} e_{2}-\dot{V}_{\mathrm{pvref}} \\
& =\frac{1}{C_{1}} i_{\mathrm{pv}}-\frac{1}{C_{1}}\left(i_{\mathrm{pv}}+C_{1} k_{1} e_{1}-C_{1} \dot{V}_{\mathrm{pvref}}\right)-\frac{1}{C_{1}} e_{2}-\dot{V}_{\mathrm{pvref}}
\end{aligned}
$$

Therefore, the system equation of the two errors is

$$
\dot{e}_{1}=-k_{1} e_{1}-\frac{1}{C_{1}} e_{2},
$$

$$
\dot{e}_{2}=\dot{x}_{2}-\dot{x}_{2}^{*}=\frac{1}{L_{B}} x_{1}-\frac{(1-u)}{L_{B}} V_{\mathrm{C} 2}-\dot{x}_{2}^{*}
$$


Choosing a second Lyapunov function candidate $V_{2}$,

$$
V_{2}=V_{1}+\frac{1}{2} e_{2}^{2}
$$

and its derivative is

$$
\dot{V}_{2}=\dot{V}_{1}+e_{2} \dot{e}_{2}=e_{1} \dot{e}_{1}+e_{2} \dot{e}_{2} .
$$

Applying (12) and (13) in equation (15), the new expression of the derivative of $V_{2}$ is mentioned in

$$
\begin{aligned}
\dot{V}_{2} & =e_{1}\left(-k_{1} e_{1}-\frac{1}{C_{1}} e_{2}\right)+e_{2}\left(\frac{1}{L_{B}} x_{1}-\frac{\left(1-u_{1}\right)}{L_{B}} V_{\mathrm{C} 2}-\dot{x}_{2}^{*}\right) \\
& =-k_{1} e_{1}^{2}+e_{2}\left(-\frac{1}{C_{1}} e_{1}+\frac{1}{L_{B}} x_{1}-\frac{\left(1-u_{1}\right)}{L_{B}} V_{\mathrm{C} 2}-\dot{x}_{2}^{*}\right) .
\end{aligned}
$$

To get $\dot{V}_{2}=-k_{1} e_{1}^{2}-k_{2} e_{2}^{2}<0$, where $k_{1}$ and $k_{2}$ are two positive constants, it is necessary to have the following:

$$
-\frac{1}{C_{1}} e_{1}+\frac{1}{L_{B}} x_{1}-\frac{\left(1-u_{1}\right)}{L_{B}} V_{\mathrm{C} 2}-\dot{x}_{2}^{*}=-k_{2} e_{2} .
$$

The control law corresponding to " $u_{1}$ " for the boost converter is defined in

$$
u_{1}=1-\frac{1}{V_{\mathrm{C} 2}}\left[x_{1}-L_{B} \dot{x}_{2}^{*}-L_{B}\left(\frac{1}{C_{1}} e_{1}-k_{2} e_{2}\right)\right] .
$$

$u_{1}$ is the duty cycle that is the input of the PWM generator issuing a suitable PWM signal to control the power transistors in the boost converter. The error $e_{1}$ tends to zero because the derivatives of $V_{1}$ and $V_{2}$ are negative functions.

3.2. Inverter with LC Filter. The single-phase inverter studied is depicted in Figure 8.

$V_{\mathrm{C} 2}$ is the DC voltage. $U_{\mathrm{AB}}$ and $U_{C}$ are the output voltage before filtering and after filtering, respectively. $i_{\mathrm{LF}}$ and $i_{0}$ are the current of the inductor $L_{F}$ and the current in the load, respectively. The switching frequency applied in electronic switches has the value of $20 \mathrm{kHz}$, and it is significantly higher than the frequency of the system which is $50 \mathrm{~Hz}$ in order to obtain a good form of output voltage of the inverter. Therefore, voltages and currents are replaced by their Root Mean Square (RMS) value. (19) and (20) represent the system model:

$$
\begin{aligned}
& C \frac{d U_{C}}{d t}=i_{\mathrm{LF}}-i_{0}, \\
& L_{F} \frac{d i_{\mathrm{LF}}}{d t}=U_{\mathrm{AB}}-U_{C} .
\end{aligned}
$$

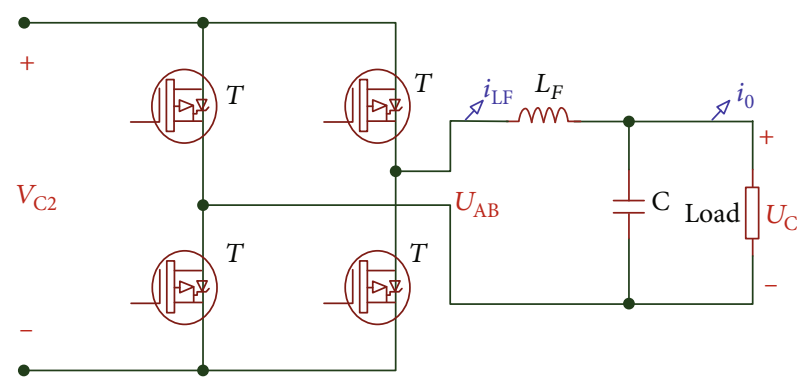

Figure 8: Basic schematic of a single-phase H-bridge inverter.

By choosing the voltage $U_{C}$ as the system state and the control parameter $u_{2}$ as the signal control of the inverter, (19) and (20) can be rearranged as

$$
\begin{aligned}
C \dot{x}_{1} & =x_{2}-i_{0}, \\
L_{F} \dot{x}_{2} & =V_{\mathrm{C} 2} u_{2}-x_{1},
\end{aligned}
$$

where $x$ is the state vector of the second-order system. $x_{1}$ and $x_{2}$ are the average values of $U_{C}$ and $i_{\mathrm{LF}}$, respectively. $u_{2}$ is the control law.

$$
\begin{aligned}
& \dot{x}_{1}=\frac{1}{C} x_{2}-\frac{1}{C} i_{0}, \\
& \dot{x}_{2}=\frac{V_{\mathrm{C} 2}}{L} u_{2}-\frac{1}{L_{F}} x_{1} .
\end{aligned}
$$

The objective is to have the sinusoidal desired output voltage at load terminals by using a back-stepping controller in order to have a closed-loop regulation. The design technique of the back-stepping controller is based on the stability theory of the Lyapunov dynamic systems. This section aims to force the output voltage $x_{1}$ to track the reference signal $U_{\text {cref }}$ with the lowest THD and high robustness. Therefore, $e_{3}$ is the error and it is defined as

$$
e_{3}=U_{c r e f}-x_{1} \text {. }
$$

The aim is to obtain $e_{3}$ equal to zero. Taking the derivative of $e_{3}$,

$$
\begin{aligned}
& \dot{e}_{3}=\dot{U}_{\text {cref }}-\dot{x}_{1}, \\
& \dot{e}_{3}=\dot{U}_{\text {cref }}-\frac{1}{C} x_{2}+\frac{1}{C} i_{0} .
\end{aligned}
$$

By choosing the following Lyapunov candidate,

$$
V_{1}=\frac{1}{2} e_{3}^{2},
$$

so that its derivative is

$$
\dot{V}_{1}=e_{3} \dot{e}_{3}=e_{3}\left(\dot{U}_{\text {cref }}-\frac{1}{C} x_{2}+\frac{1}{C} i_{0}\right),
$$


where the second error is defined as

$$
\begin{aligned}
& e_{4}=\alpha-x_{2}, \\
& x_{2}=\alpha-e_{4},
\end{aligned}
$$

so that its derivative is

$$
\dot{e}_{4}=\dot{\alpha}-\dot{x}_{2}=\dot{\alpha}-\frac{V_{\mathrm{C} 2}}{L_{F}} u_{2}+\frac{1}{L} x_{1} .
$$

From (26) and (28),

$$
\dot{V}_{1}=e_{3}\left(\dot{U}_{\text {cref }}-\frac{1}{C} \alpha-\frac{1}{C} e_{4}+\frac{1}{C} i_{0}\right) \text {. }
$$

To get $\dot{V}_{1}<0$, choose $\alpha$ such that

$$
\alpha=C\left(\dot{U}_{\mathrm{cref}}+\frac{1}{C} i_{0}+k_{3} e_{3}\right)
$$

where $k_{3}>0$, then

$$
\begin{aligned}
& \dot{V}_{1}=e_{3}\left(\dot{U}_{\text {cref }}-\dot{U}_{\text {cref }}-\frac{1}{C} i_{0}-k_{3} e_{3}+\frac{1}{C} e_{4}+\frac{1}{C} i_{0}\right), \\
& \dot{V}_{1}=e_{3}\left(-k_{3} e_{3}+\frac{1}{C} e_{4}\right), \\
& \dot{V}_{1}=e_{3} \dot{e}_{3} .
\end{aligned}
$$

Therefore,

$$
\dot{e}_{3}=-k_{3} e_{3}+\frac{1}{C} e_{4}
$$

Choosing a second Lyapunov function candidate,

$$
V_{2}=V_{1}+\frac{1}{2} e_{4}^{2}
$$

and its derivative is

$$
\dot{V}_{2}=\dot{V}_{1}+e_{4} \dot{e}_{4}
$$

Basing on equations (33) and (37), we can get $\dot{V}_{2}$ :

$$
\begin{aligned}
& \dot{V}_{2}=-k_{3} e_{3}^{2}+\frac{1}{C} e_{3} e_{4}+e_{4} \dot{e}_{4}, \\
& \dot{V}_{2}=-k_{3} e_{3}^{2}+e_{4}\left(\frac{1}{C} e_{3}+\dot{e}_{4}\right) .
\end{aligned}
$$

As a result, from (29) and (39), the expression of $\dot{V}_{2}$ is

$$
\dot{V}_{2}=-k_{3} e_{3}^{2}+e_{4}\left(\frac{1}{C} e_{3}+\dot{\alpha}-\frac{V_{\mathrm{C} 2}}{L_{F}} u_{2}+\frac{1}{L_{F}} x_{1}\right)
$$

The derivative of $\alpha$ from equation (31) is

$$
\dot{\alpha}=C\left(\ddot{U}_{\text {cref }}+\frac{1}{C} \dot{i}_{0}+k_{3} \dot{e}_{3}\right)
$$

Therefore, the final expression of $\dot{V}_{2}$ is

$$
\dot{V}_{2}=-k_{3} e_{3}^{2}+z_{2}\left(\frac{1}{C} e_{3}+C \ddot{U}_{\text {cref }}+\dot{i}_{0}+C k_{3} \dot{e}_{3}-\frac{V_{\mathrm{C} 2}}{L_{F}} u_{2}+\frac{1}{L_{F}} x_{1}\right) \text {. }
$$

To get $\dot{V}_{2}<0$, choose the control law " $u_{2}$ " for the inverter as defined in equation (43), where $k_{4}>0$ :

$$
u_{2}=\frac{L_{F}}{V_{\mathrm{C} 2}}\left(\frac{1}{C} e_{3}+C \ddot{U}_{\mathrm{cref}}+\dot{\dot{i}}_{0}+C k_{3} \dot{e}_{3}+\frac{1}{L_{F}} x_{1}+k_{4} e_{4}\right) \text {. }
$$

By applying this control law to the PWM inverter in the standalone system, the error $e_{3}$ tends to zero because the derivatives of $V_{1}$ and $V_{2}$ are negative functions. According to the Lyapunov theory, choose $k_{3}>0$ and $k_{4}>0$ to ensure good stability of the back-stepping control for the inverter.

\section{Simulation and Results}

Figure 9 shows the circuit schematic of the PV inverter in the standalone mode simulated in the Simulink platform. At the beginning of the simulation, the resistor $R_{1}$ is the only consumer of the solar energy generated by the PV array. After 0.65 seconds, another resistive load $R_{2}$ is added in parallel for an additional $0.1 \mathrm{sec}$. At $0.75 \mathrm{sec}, R_{2}$ is disconnected from the load and only $R_{1}$ remains connected. Parameters of the PV module used in this study are listed in Table 1 . The overall system is tested and validated with parameters of the system which are listed in Table 2.

The type of PWM block used in Simulink for both the boost converter and the inverter is the PWM generator DC-DC and single-phase half-bridge (2 pulses), respectively. The minimum and maximum values of the input PWM generator for the inverter, which is the control law $u_{2}$, are -1 and 1 , respectively.

The internal design blocs of back-stepping control numbers 1 and 2 are shown, respectively, in Figures 10 and 11. The control law equation can be presented in the form of blocks.

The initial value of irradiance is set to $600 \mathrm{~W} / \mathrm{m}^{2}$; after each $0.2 \mathrm{~s}$, it is changed to the following values: $200 \mathrm{~W} / \mathrm{m}^{2}$, $700 \mathrm{~W} / \mathrm{m}^{2}, 1000 \mathrm{~W} / \mathrm{m}^{2}$, and $900 \mathrm{~W} / \mathrm{m}^{2}$ in order to have instantaneous step values of irradiance in a short time for testing the capability of the controller to track the suitable value of power generated by the PV array. During this simulation, the temperature is kept at $25^{\circ} \mathrm{C}$. Figure 12 shows the sun irradiance profile that is applied to the PV array with the aim of simulating the proposed system in different conditions and to examine the dynamic response of the two backstepping controllers. 


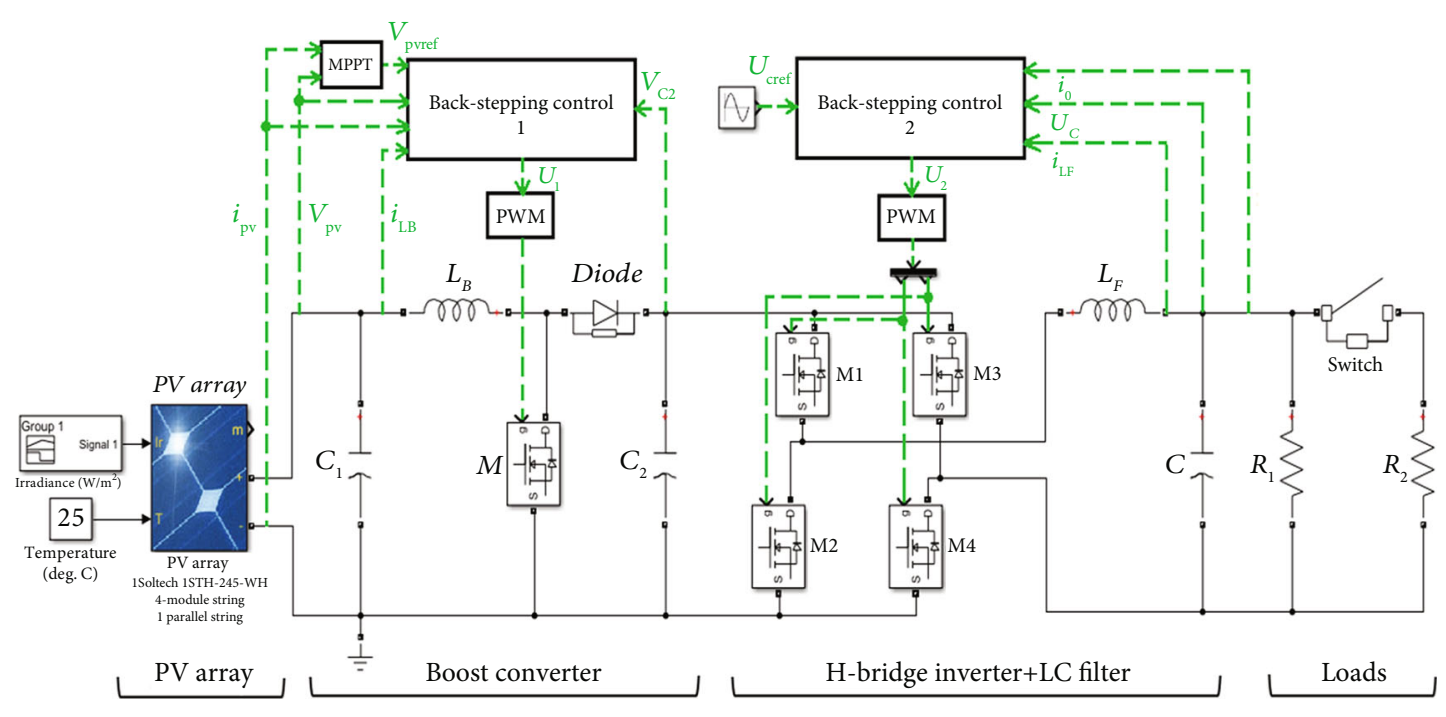

FIgURE 9: Schematic of the proposed PV inverter system.

TABle 2: Parameters of the system elements.

\begin{tabular}{lc}
\hline Parameter & Value \\
\hline$U_{\text {cref }}($ RMS $)$ & $220 \mathrm{~V}$ \\
$F_{\text {PWM }}$ & $20 \mathrm{kHz}$ \\
$f$ & $50 \mathrm{~Hz}$ \\
$R_{1}$ & $100 \Omega$ \\
$R_{2}$ & $100 \Omega$ \\
Offset (MPPT bloc) & $0.0005 \mathrm{~V}$ \\
$C$ & $47 e-6 \mathrm{~F}$ \\
$C_{1}$ & $100 e-6 \mathrm{~F}$ \\
$C_{2}$ & $100 e-6 \mathrm{~F}$ \\
$L_{F}$ & $4.7 e-3 \mathrm{H}$ \\
$L_{B}$ & $3 e-3 \mathrm{H}$ \\
$T$ & $25^{\circ} \mathrm{C}$ \\
$k_{1}$ & 9000 \\
$k_{2}$ & 9000 \\
$k_{3}$ & 20000 \\
$k_{4}$ & 30000 \\
Sample time & $1 e-6 \mathrm{~s}$ \\
Switch on & $0.65-0.75 \mathrm{~s}$ \\
\hline &
\end{tabular}

As shown in Figure 13, the MPPT algorithm block generates successfully the corresponding peak voltage $V_{\text {pvref }}$ to be used later by the back-stepping controller. At the beginning of simulation, the PV array voltage $V_{\mathrm{pv}}$ started at $0 \mathrm{~V}$ value and it attained the initial value of the $V_{\text {prref }}$ which is $121 \mathrm{~V}$ with $2 \mathrm{~V}$ of ripples in the transitory regime that lasted $10 \mathrm{~ms}$. Until $0.2 \mathrm{~s}$, the ripples of $V_{\mathrm{pv}}$ are $0.6 \mathrm{~V}$ in the steady state. At $0.2 \mathrm{~s}$, there is a change of solar irradiance from 600 to $200 \mathrm{~W} / \mathrm{m}^{2}$ which causes a slight decrease in refer- ence voltage from $121 \mathrm{~V}$ to $118 \mathrm{~V}$; also, the value of the PV array voltage $V_{\text {pv }}$ successfully tracks the $V_{\text {pvref }}$. It can be seen from Figure 13 that the PV array voltage $V_{\mathrm{pv}}$ is changed due to the variation of solar irradiance and it follows the reference voltage $V_{\text {pvref }}$ with some disturbances in the transitory regime due to the low performance of using the basic $\mathrm{P} \& \mathrm{O}$ algorithm.

The variation of irradiance causes little variation in the PV voltage and high variation in the PV current. Figure 14 shows that the current generated by PV array $i_{\mathrm{pv}}$ is variated with a big jump between two values against the voltage which varies with a small difference. At the start, the current value $i_{\mathrm{pv}}$ is set at $5.2 \mathrm{~A}$ and it became stable after $15 \mathrm{~ms}$ from the beginning at $4.85 \mathrm{~A}$ in the steady state. At $0.4 \mathrm{~s}$, the irradiance is changed from 200 to $700 \mathrm{~W} / \mathrm{m}^{2}$ which causes the rapid increase in current value with some ripples in the transitory regime that lasted only $6 \mathrm{~ms}$; the new current value is $5.68 \mathrm{~A}$ at $700 \mathrm{~W} / \mathrm{m}^{2}$.

Similarly, Figure 15 shows the photovoltaic power of the PV array during $1 \mathrm{~s}$ according to the solar irradiance profile chosen in Figure 12. At the beginning, the sun irradiance is set at $600 \mathrm{~W} / \mathrm{m}^{2}$ that means that the reference power generated by the PV array is $589 \mathrm{~W}$. The power value is $0 \mathrm{~W}$, and the back-stepping controller starts executing its role which makes the PV array generate the power for different atmospheric conditions. The transient phase contains little ripples of $20 \mathrm{~W}$, and this controller can create a suitable control to the boost converter to track the reference power. For this type of power supply application, the overshoot of our MPPT system is around $40 \mathrm{~W}$, in the transient phase, in which the value can be considered as negligible compared to the total power of the system which is $1 \mathrm{~kW}$. The transient phase contains little ripples of $20 \mathrm{~W}$, and this controller can create a suitable control to the boost converter to track the reference power. After $7 \mathrm{~ms}$ from starting the simulation, the power generated by the PV array is $588 \mathrm{~W}$. At $0.2 \mathrm{~s}$, the irradiance changed its value and it became $200 \mathrm{~W} / \mathrm{m}^{2}$ and automatically the power 


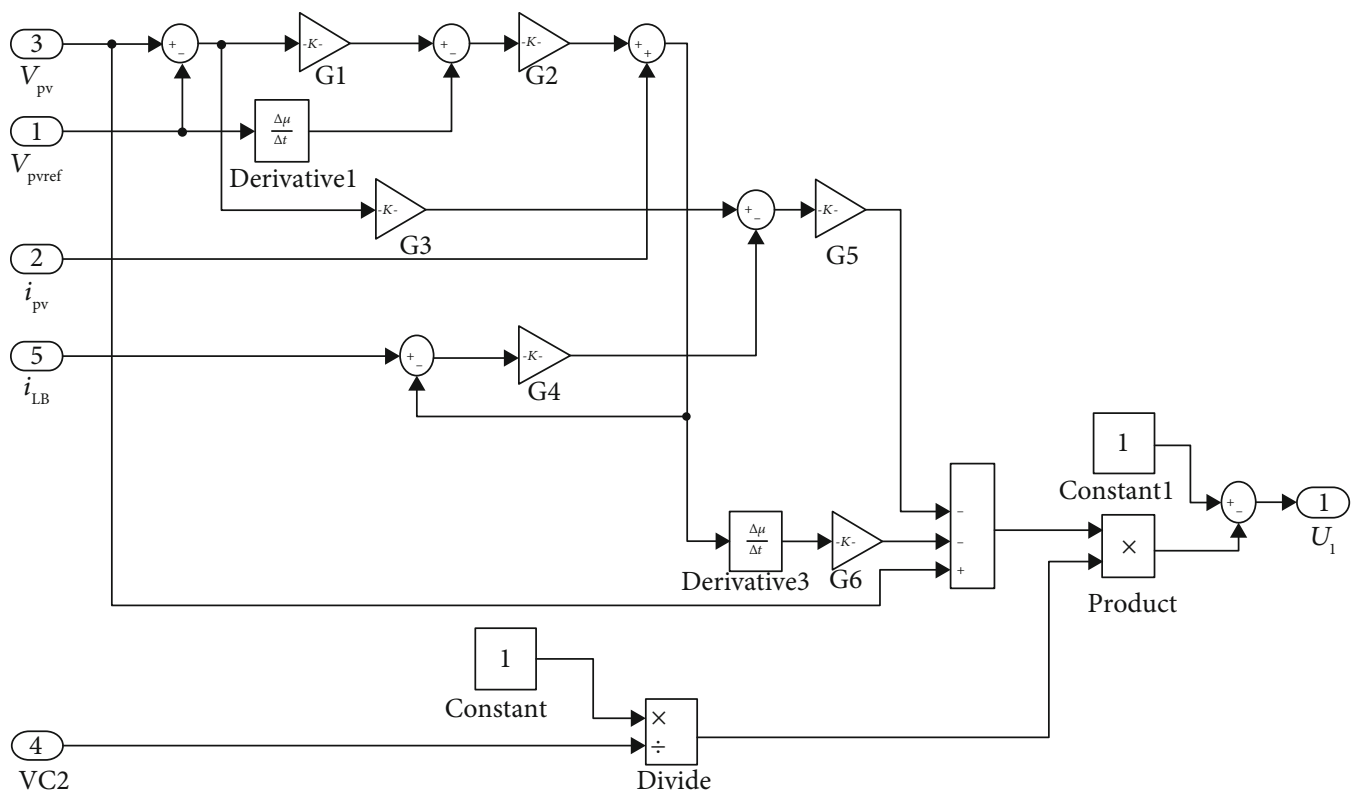

Figure 10: Internal blocs of back-stepping control 1.

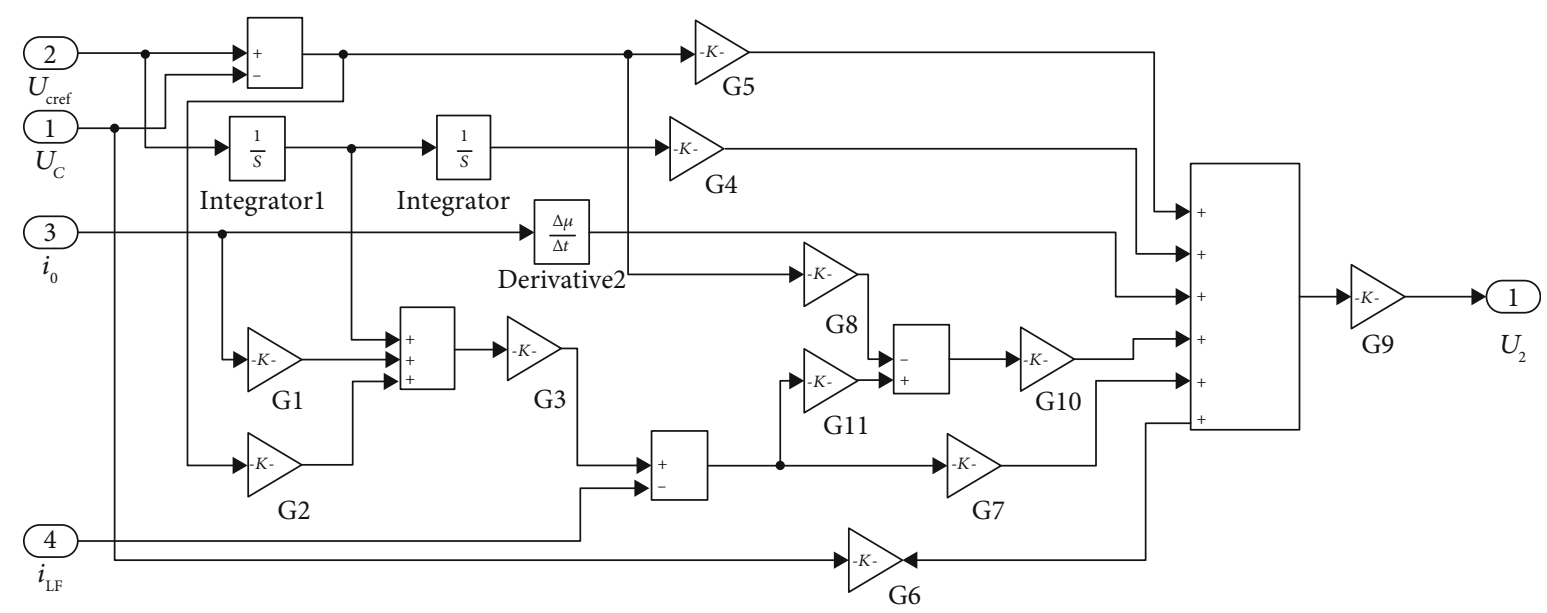

Figure 11: Internal blocs of back-stepping control 2.

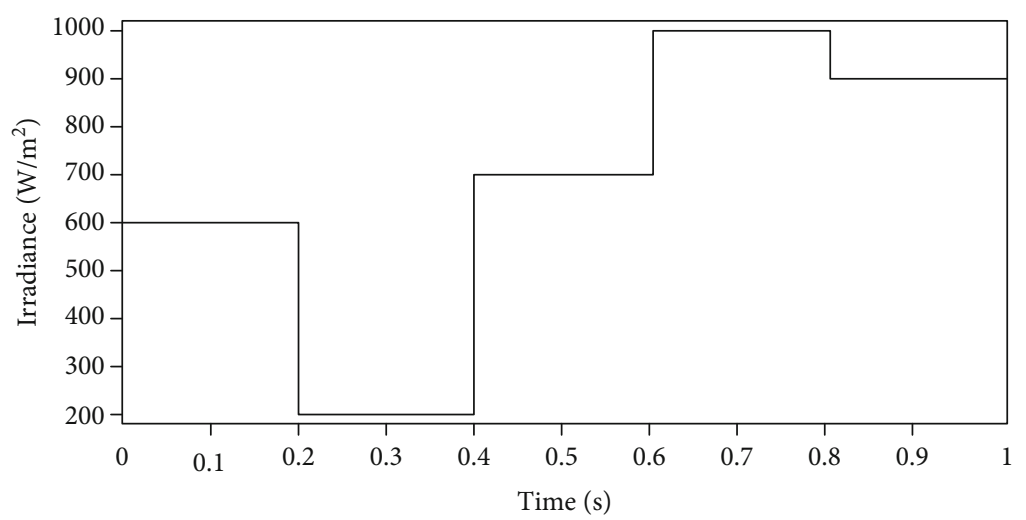

FIGURE 12: Sun irradiance profile. 


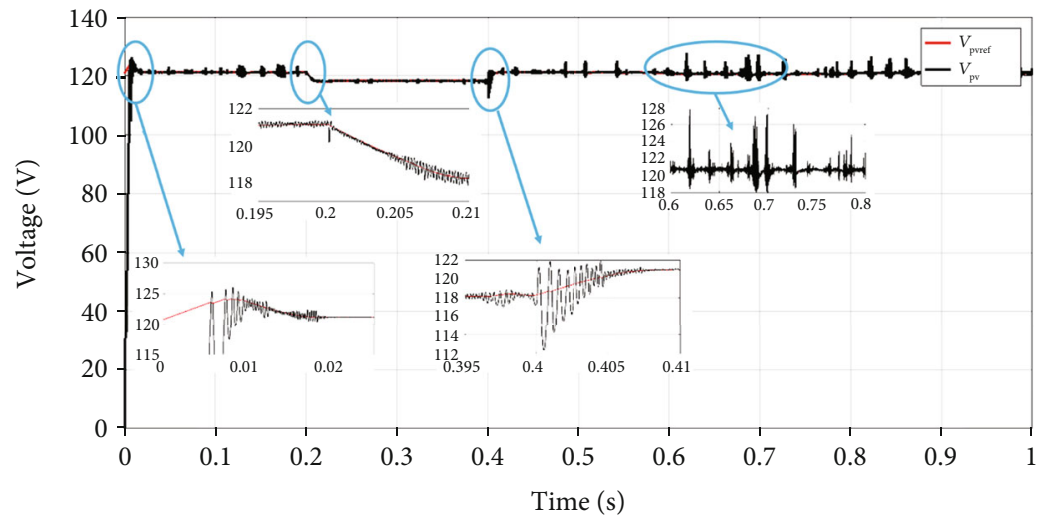

FIGURE 13: PV array voltage with its reference.

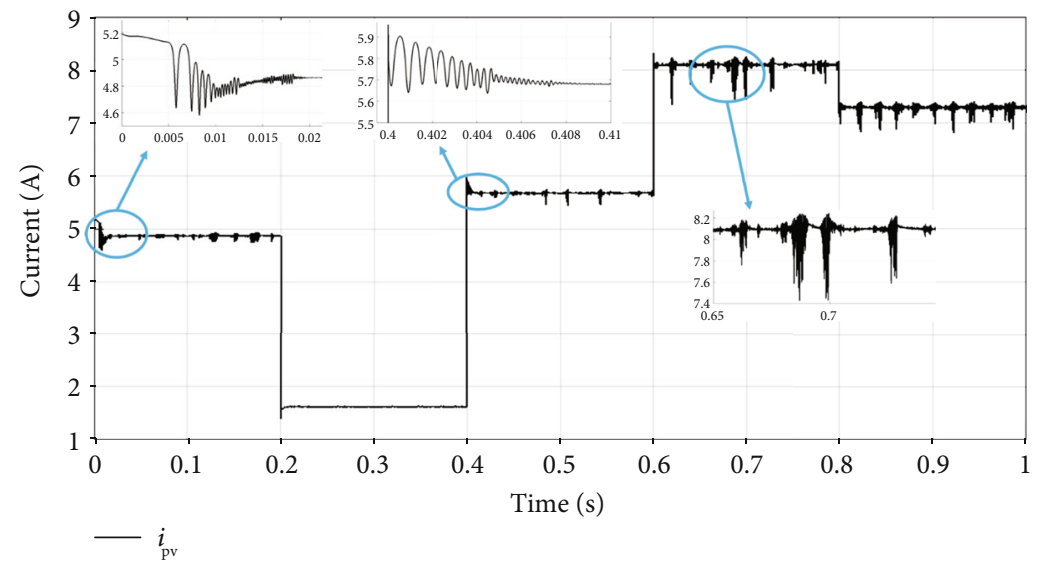

Figure 14: PV array current.

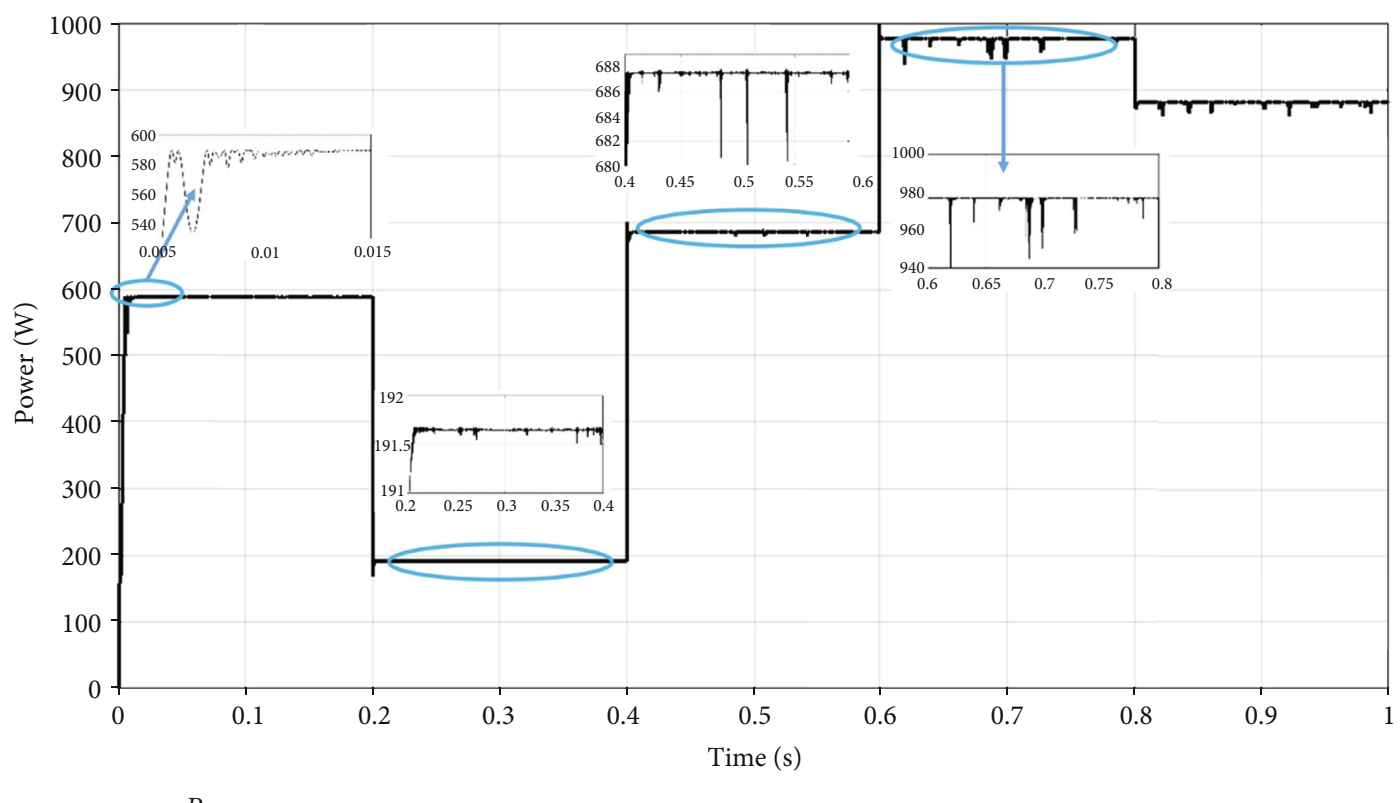

FIGURE 15: PV array power. 


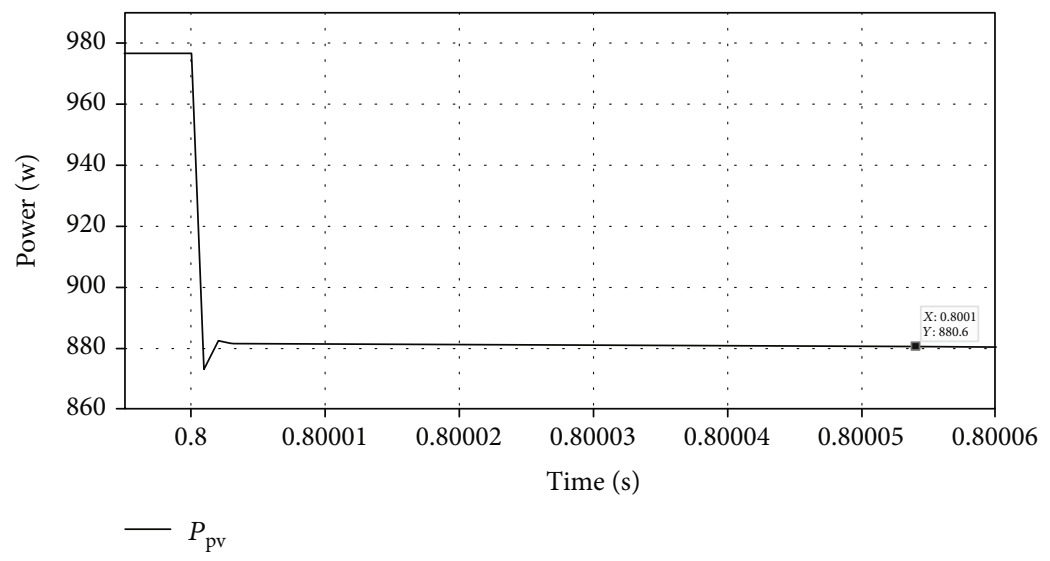

Figure 16: Zoom area of the PV array power.

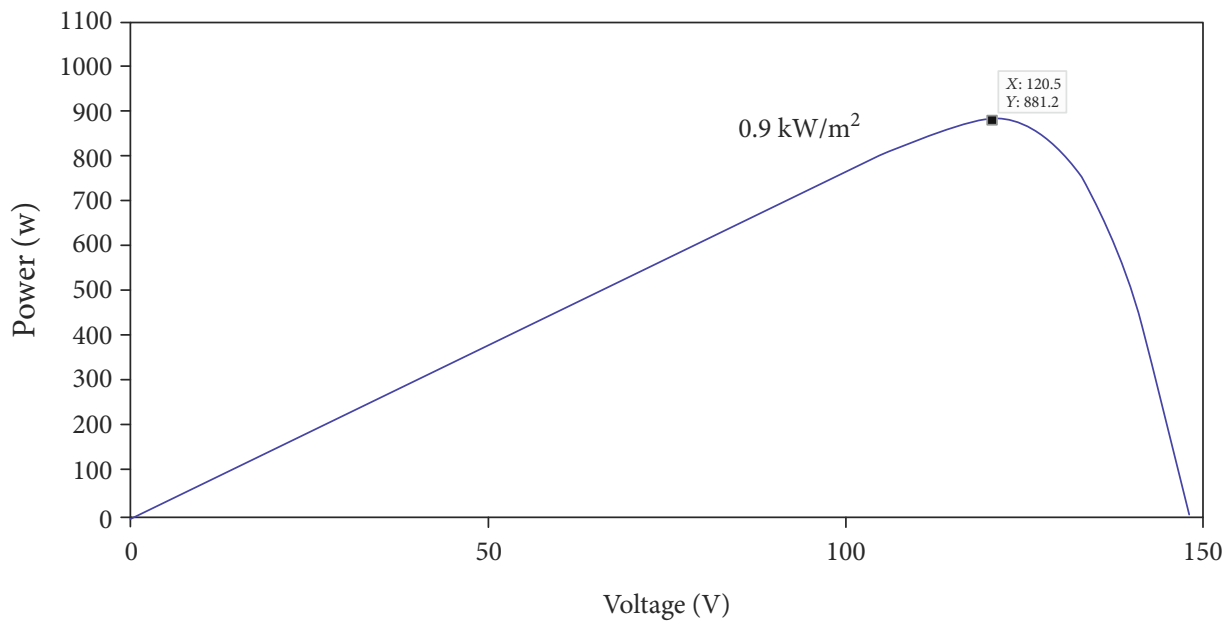

Figure 17: P-V characteristic of the PV array for $900 \mathrm{~W} / \mathrm{m}^{2}$.

will decrease; therefore, the new value of the power generated by the PV array is $191.6 \mathrm{~W}$. At $0.4 \mathrm{~s}$, the power value is $687 \mathrm{~W}$ and it corresponds to $700 \mathrm{~W} / \mathrm{m}^{2}$ of sun irradiance. For $1000 \mathrm{~W} / \mathrm{m}^{2}$, the power increases and it becomes $978.2 \mathrm{~W}$, in the last part or the last value of irradiance which is $900 \mathrm{~W} / \mathrm{m}^{2}$. At $0.8 \mathrm{~s}$, the sun irradiance changes from 1000 to $900 \mathrm{~W} / \mathrm{m}^{2}$ which causes diminution in power. Figure 16 shows a zoom of $P_{\mathrm{pv}}$ between 0.8 and $0.80006 \mathrm{~s}$; therefore, the response time to attain the exact value of the power is around $1 \mathrm{~ms}$. Figure 17 gives an idea about the maximum power at $900 \mathrm{~W} / \mathrm{m}^{2}$ that is $881.2 \mathrm{~W}$. Referring to Figures 16 and 17 , the efficiency of the MPPT system is $99.93 \%$. Moreover, the MPP is successfully tracked by the controller which verifies the high robustness and performance of the backstepping control to generate the maximum power to the load.

Figure 18 shows the performance of the inverter with the proposed back-stepping controller. This figure represents two waveforms which are the output voltage of the inverter at the terminal load $U_{C}$ and the sinusoidal signal reference $U_{\text {cref }}$. At the beginning, the irradiance value was $600 \mathrm{~W} / \mathrm{m}^{2}$ and the output voltage of the boost converter increased until it became greater than $311 \mathrm{~V}$ which is the nominal value of the input inverter.
Figure 19 presents a zoom of the output voltage of the inverter between 0 and $0.1 \mathrm{~s}$ to show that the inverter follows perfectly the reference voltage using the back-stepping control. For our inverter, as mentioned in Figure 19, the response time to have a good form of the output voltage for electrical loads is $30 \mathrm{~ms}$ at the beginning in which the power generated by the PV array is $589 \mathrm{~W}$. Moreover, in this time, the RMS value of the output voltage of the inverter is less than the norm $230 \mathrm{~V}$. Therefore, this transient phase has no effect on power quality in electrical loads. There is distortion of output voltage $U_{C}$ until $40 \mathrm{~ms}$. This is due to insufficient voltage in the input of the inverter and not to the back-stepping control. After $40 \mathrm{~ms}$ from the beginning, the input voltage of the inverter becomes greater than $311 \mathrm{~V}$ and the output voltage of inverter $U_{C}$ started to track the reference voltage $U_{\text {cref }}$. Moreover, with the input voltage of the inverter greater than $311 \mathrm{~V}$, the response time of this controller is less than $15 \mathrm{~ms}$ that ensures the high robustness of this controller. At $0.2 \mathrm{~s}$, the solar irradiance became $200 \mathrm{~W} / \mathrm{m}^{2}$ which means less power generated by the PV array. Therefore, the boost converter was not able to provide a suitable voltage to the inverter and the voltage was less than $311 \mathrm{~V}$. For this reason, a voltage drop appeared in the output voltage of the inverter 


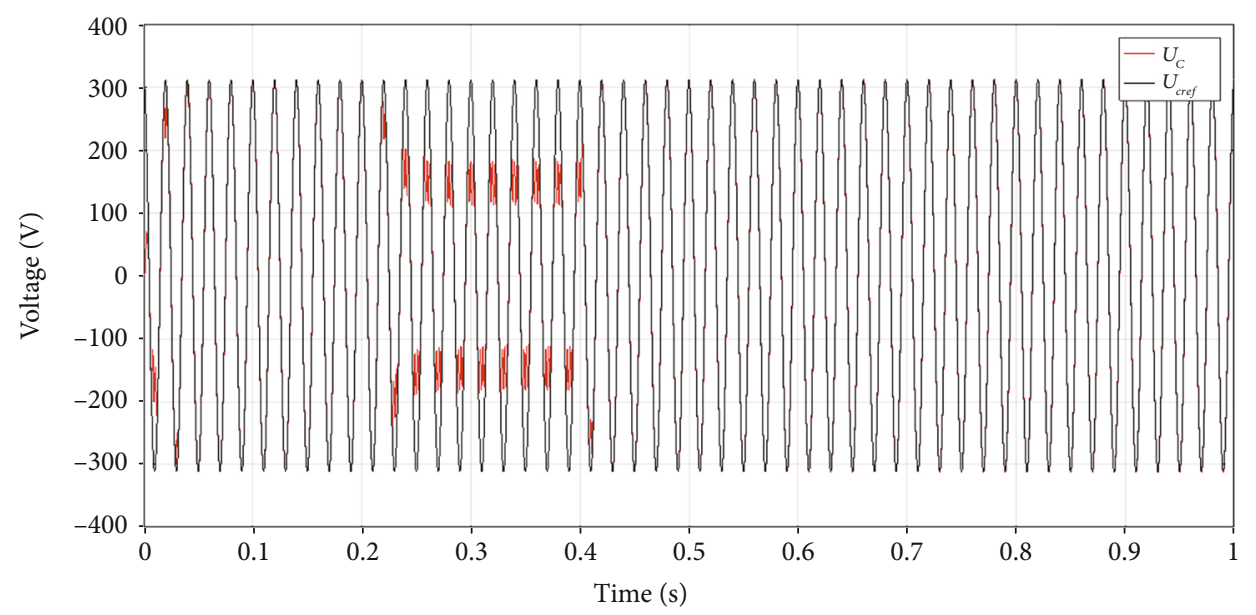

FIGURE 18: Output voltage inverter after filtering with its reference.

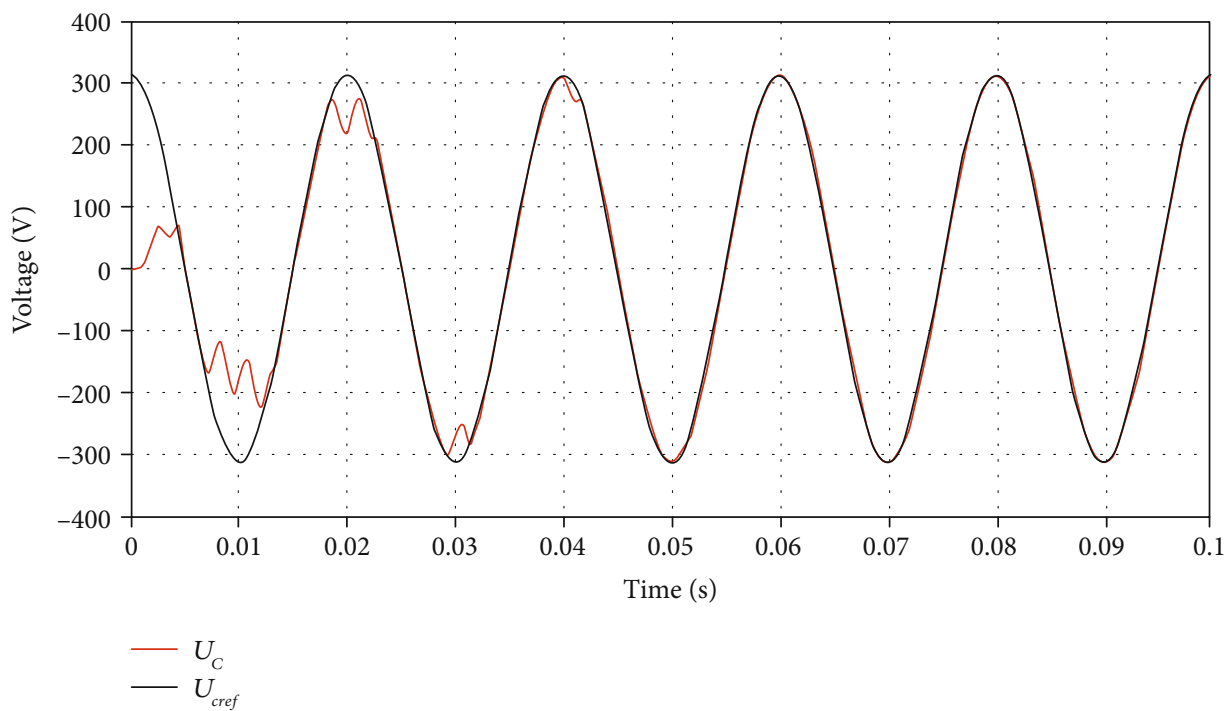

FIGURE 19: Output voltage inverter after filtering with its reference (zoom area).

as show in Figure 18 between 0.2 and $0.4 \mathrm{~s}$. After $0.4 \mathrm{~s}$, the solar irradiance increased, and automatically, the power increased. Therefore, there is no issue with voltage drop despite the addition of a second resistive load.

Figure 20 shows the current curve $i_{0}$ of the AC loads. This figure represents the pure sinusoidal waveform of the current consumed by loads. Between 0.2 and $0.4 \mathrm{~s}$, there is a current drop due to the insufficient current produced by the PV array. At $0.65 \mathrm{~s}$, there are two loads in parallel. It can be seen from Figure 20 that the current increased to $6.2 \mathrm{~A}$ as a maximum value; after $0.75 \mathrm{~s}$, it decreased to $3.1 \mathrm{~A}$ as a maximum value. The controller of the second part of the proposed inverter is robust, and it shows the robustness and high performance of the chosen controller.

Figure 21 shows the frequency analysis of the inverter's output voltage. The fundamental is about $310.7 \mathrm{~V}$ at a frequency of $50 \mathrm{~Hz}$, and the THD is about $0.78 \%$. From Figures $18-21$, we can conclude that the inverter studied with the proposed back-stepping control in the standalone mode has a low harmonic distortion, high conversion efficiency, strong control performance, and a high quality of sinusoidal waveform.

The efficiency of the MPPT system and the efficiency of the inverter are mentioned in Table 3 in different values of solar irradiation. As shown for different solar irradiance levels, our first controller of the MPPT system presents a high percentage of efficiency and a good manner to track the power compared with other works as mentioned in $[12,14]$. For the second stage which is the inverter, it also presents good and high efficiency, only that there is a certain limit of solar irradiance wherein the inverter cannot generate a good waveform of voltage to loads. As shown, the efficiency in $200 \mathrm{~W} / \mathrm{m}^{2}$ is bad because the input power of the inverter is less than the threshold power that must be generated by the PV array.

Table 4 shows the performance comparison of MPPT algorithms between our system and other works. The $1 \mathrm{~ms}$ of the response time and the $99.93 \%$ of efficiency 


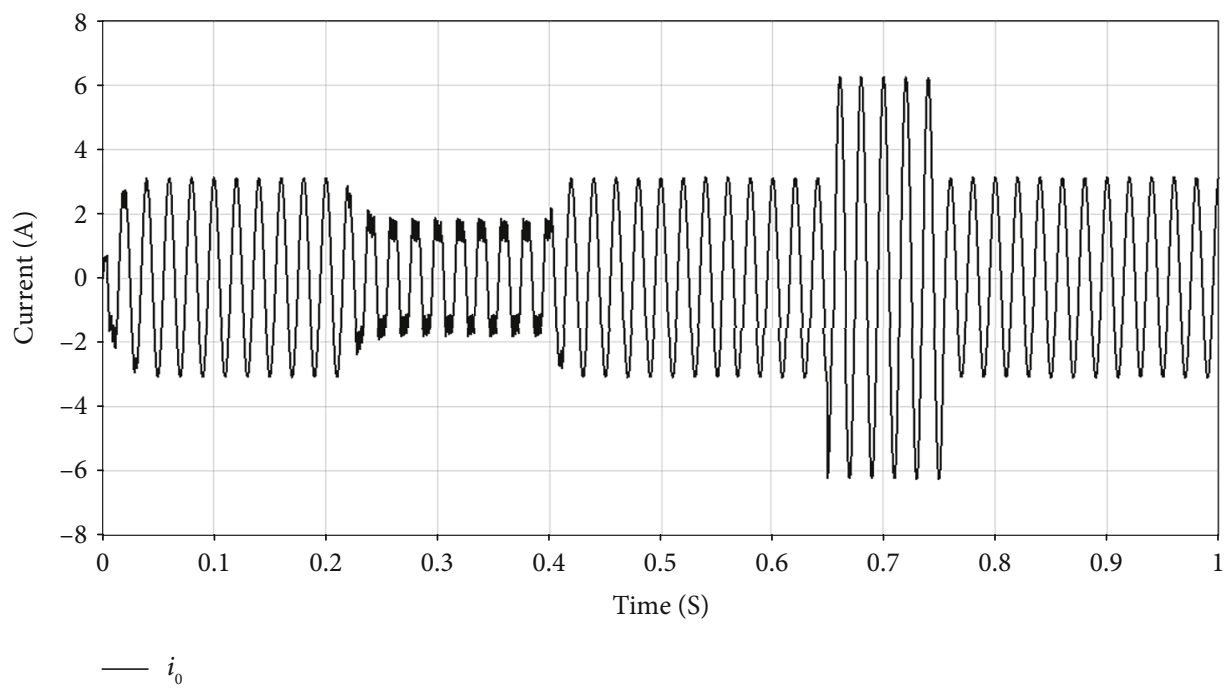

Figure 20: Current consumed by the loads.

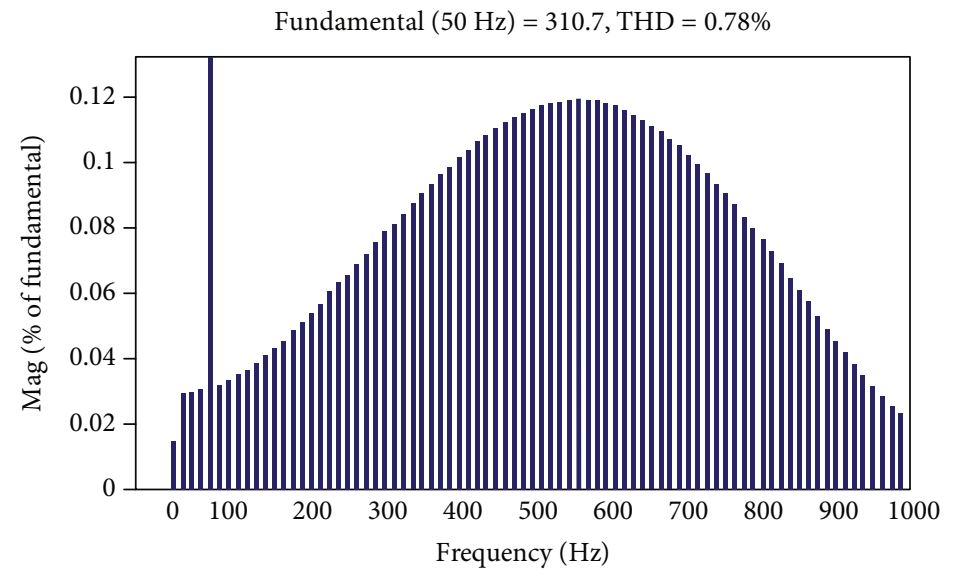

FIGURE 21: Frequency analysis of the output voltage inverter.

TABLE 3: Efficiency of two stages of the whole system under different solar irradiation values.

\begin{tabular}{lcc}
\hline $\begin{array}{l}\text { Solar irradiation } \\
\left(\mathrm{W} / \mathrm{m}^{2}\right)\end{array}$ & $\begin{array}{c}\text { Efficiency of MPPT } \\
(\%)\end{array}$ & $\begin{array}{c}\text { Efficiency of inverter } \\
(\%)\end{array}$ \\
\hline 200 & 99.68 & 71.00 \\
600 & 99.83 & 95.40 \\
700 & 99.92 & 95.82 \\
900 & 99.93 & 96.80 \\
1000 & 99.96 & 96.88 \\
\hline
\end{tabular}

demonstrate the high performance and robustness of $\mathrm{P} \& \mathrm{O}$ with back-stepping algorithm of our MPPT system.

In order to easily exhibit the excellence and to show the performance of the proposed back-stepping in the standalone mode, the results of the PV inverter with other works $[17,29-33]$ are summarized in Table 5. As shown in this comparison, our proposed system has good and high performance control to extract the maximum power generated by the PV array and to regulate the output voltage of the inverter. Firstly, the function performed by our system is a conversion of energy from photovoltaic modules to the use of this energy by electric charges. It is a dual function or double role between tracking the maximum power and regulating the voltage to have a sinusoidal waveform at the output of the inverter. However, most works deal only with the DC to AC conversion without MPPT [34]. With a very low THD and a very advanced nonlinear controller, our system is the most practical for the realization of photovoltaic inverters in the standalone mode.

\section{Conclusion}

A robust control scheme combined with a high performance PV inverter system has been presented in this paper. Simulation results show that the two stages of converter successfully respond to the two principal objectives which are, firstly, the extraction of the maximum power from the PV array with an efficiency of $99.93 \%$ and $1 \mathrm{~ms}$ of response time to show the 
TABLE 4: Performance comparison of MPPT algorithms.

\begin{tabular}{lccc}
\hline Ref. & Algorithm type & Response time & Efficiency \\
\hline & P\&O algorithm & - & - \\
$96 \%$ \\
{$[10]$} & PI & - & $96.5 \%$ \\
& Neuro-fuzzy & - & $98.2 \%$ \\
{$[12]$} & Back-stepping & $7 \mathrm{~ms}$ & $99.1 \%$ \\
{$[14]$} & Proposed modified incremental conductance & $2.17 \mathrm{~ms}$ & - \\
Our study & Integral back-stepping & $1 \mathrm{~ms}$ & $97.53 \%$ \\
\hline
\end{tabular}

TABLE 5: Quality comparisons of the whole system with other proposal work.

\begin{tabular}{|c|c|c|c|c|c|c|c|c|}
\hline Ref & Function & $\begin{array}{l}\text { Standalone/grid } \\
\text { connected }\end{array}$ & MPPT & Transformer & $\begin{array}{l}\text { Powered } \\
\text { from }\end{array}$ & THD & Control type & $\begin{array}{c}\text { System } \\
\text { robustness }\end{array}$ \\
\hline [29] & $\mathrm{DC}$ to $\mathrm{AC}$ & Standalone & No & Yes & $\begin{array}{l}\text { Battery } \\
\text { source }\end{array}$ & $\begin{array}{c}\text { THD } \\
\text { voltage } 2 \%\end{array}$ & $\begin{array}{c}\text { Multilevel } \\
\text { PWM control }\end{array}$ & Fair \\
\hline [30] & $\begin{array}{c}\mathrm{MPPT}+\mathrm{DC} \\
\text { to } \mathrm{AC}\end{array}$ & Standalone & Yes & Yes & PV source & - & Proposed MPPT & Fair \\
\hline [31] & $\begin{array}{c}\mathrm{MPPT}+\mathrm{DC} \\
\text { to } \mathrm{AC}\end{array}$ & Standalone & Yes & No & PV source & $\begin{array}{c}\text { THD } \\
\text { voltage } 2.7 \%\end{array}$ & SPWM & Poor \\
\hline [17] & $\mathrm{DC}$ to $\mathrm{AC}$ & $\begin{array}{l}\text { Standalone+ } \\
\text { grid connected }\end{array}$ & No & No & $\begin{array}{l}\text { Battery } \\
\text { source }\end{array}$ & $\begin{array}{c}\text { THD } \\
\text { voltage } 1.29 \%\end{array}$ & Back-stepping & Favorable \\
\hline$[32]$ & $\mathrm{DC}$ to $\mathrm{AC}$ & Standalone & No & No & $\begin{array}{l}\text { Battery } \\
\text { source }\end{array}$ & - & $\begin{array}{c}\text { Direct quadrature } \\
\text { and droop Lyapunov }\end{array}$ & Fair \\
\hline [33] & $\mathrm{DC}$ to $\mathrm{AC}$ & Grid connected & No & No & $\begin{array}{c}\text { Renewable } \\
\text { energy source }\end{array}$ & $\begin{array}{l}\text { Current } \\
\text { THD } 4.5 \%\end{array}$ & Direct quadrature & Fair \\
\hline Our study & $\begin{array}{c}\mathrm{MPPT}+\mathrm{DC} \\
\text { to } \mathrm{AC}\end{array}$ & Standalone & Yes & No & PV source & $\begin{array}{c}\text { THD voltage } \\
0.78 \%\end{array}$ & Back-stepping & Favorable \\
\hline
\end{tabular}

fast dynamic response of our MPPT algorithm using the boost converter in order to avoid the use of the transformer. Secondly, we obtained a stable sinusoidal waveform of the output voltage of the inverter which is $220 \mathrm{~V}$ with $0.78 \%$ of the THD and fixed $50 \mathrm{~Hz}$ frequency. This performance is obtained by using a nonlinear back-stepping control which can quickly track the reference by having the error converge to zero. This PV inverter system delivers the high quality sinusoidal power to the AC load as long as the solar radiation is higher than $300 \mathrm{~W} / \mathrm{m}^{2}$.

\section{Data Availability}

There is no underlying data in the research article.

\section{Disclosure}

The authors would to thank the organizers of the International Conference on Wireless Technologies, Embedded and Intelligent Systems (WITS 2019) which was organized on April 3-4, 2019, in Fez, Morocco. All accepted papers in this conference were published on IEEE Xplore; among those items accepted was our article titled "Control of Single Phase Inverter Using Back-Stepping in Stand-Alone Mode" which was the basis to accomplish other work that is presented in this paper.

\section{Conflicts of Interest}

The authors declare that there is no conflict of interest regarding the publication of this paper.

\section{References}

[1] B. R. Lin and J. Y. Dong, "New zero-voltage switching DC-DC converter for renewable energy conversion systems," IET Power Electronics, vol. 5, no. 4, pp. 393-400, 2012.

[2] S. Sharma and B. Singh, "Control of permanent magnet synchronous generator-based stand-alone wind energy conversion system," IET Power Electronics, vol. 5, no. 8, pp. 15191526, 2012.

[3] Statista website, "World power consumption," https://www .statista.com/statistics/280704/world-power-consumption/.

[4] M. Morales-Caporal, J. Rangel-Magdaleno, H. Peregrina-Barreto, and R. Morales-Caporal, "FPGA-in-the-loop simulation of a grid-connected photovoltaic system by using a predictive control," Electrical Engineering, vol. 100, no. 3, pp. 1327$1337,2018$.

[5] Y. Yang and F. Blaabjerg, "Overview of single-phase gridconnected photovoltaic systems," in Renewable Energy Devices and Systems with Simulations in MATLAB ${ }^{\circledR}$ and $A N S Y S^{\circledR}, \mathrm{F}$. Blaabjerg and D. M. Ionel, Eds., pp. 41-66, CRC Press, Boca Raton, FL, USA, 2017. 
[6] A. H. Mollah, P. G. K. Panda, and P. P. KSaha, "Single phase grid-connected inverter for photovoltaic system with maximum power point tracking," International Journal of Advanced Research in Electrical, Electronics and Instrumentation Engineering, vol. 4, no. 2, pp. 648-655, 2015.

[7] L. Hassaine, Power Converters and Control of Grid-Connected Photovoltaic Systems, Springer International Publishing, Cham, Switzerland, 2016.

[8] Z. Zeng, H. Yang, R. Zhao, and C. Cheng, "Topologies and control strategies of multi-functional grid-connected inverters for power quality enhancement: a comprehensive review," Renewable and Sustainable Energy Reviews, vol. 24, pp. 223270, 2013.

[9] R. Ayop and C. W. Tan, "Design of boost converter based on maximum power point resistance for photovoltaic applications," Solar Energy, vol. 160, pp. 322-335, 2018.

[10] A. D. Martin and J. R. Vazquez, "MPPT algorithms comparison in PV systems: P\&O, PI, neuro-fuzzy and backstepping controls," in 2015 IEEE International Conference on Industrial Technology (ICIT), pp. 2841-2847, Seville, Spain, 2015.

[11] J. Ahmad, "A fractional open circuit voltage based maximum power point tracker for photovoltaic arrays," in 2010 2nd International Conference on Software Technology and Engineering, pp. 247-250, San Juan, PR, USA, 2010.

[12] S. Motahhir, A. El Hammoumi, and A. El Ghzizal, "Photovoltaic system with quantitative comparative between an improved MPPT and existing INC and P\&O methods under fast varying of solar irradiation," Energy Reports, vol. 4, pp. 341-350, 2018.

[13] Y. Cheddadi, F. Errahimi, and N. Es-sbai, "Design and verification of photovoltaic MPPT algorithm as an automotive-based embedded software," Solar Energy, vol. 171, pp. 414-425, 2018.

[14] M. Arsalan, R. Iftikhar, I. Ahmad, A. Hasan, K. Sabahat, and A. Javeria, "MPPT for photovoltaic system using nonlinear backstepping controller with integral action," Solar Energy, vol. 170, pp. 192-200, 2018.

[15] M. Kaouane, A. Boukhelifa, and A. Cheriti, "Regulated output voltage double switch Buck-Boost converter for photovoltaic energy application," International Journal of Hydrogen Energy, vol. 41, no. 45, pp. 20847-20857, 2016.

[16] A. Mohd, E. Ortjohann, W. Sinsukthavorn, M. Lingemann, N. Hamsic, and D. Morton, "Inverter-based distributed generation control using droop/isochronous load sharing," IFAC Proceedings Volumes, vol. 42, no. 9, pp. 368-373, 2009.

[17] R.-J. Wai, C.-Y. Lin, H.-N. Huang, and W.-C. Wu, "Design of backstepping control for high-performance inverter with stand-alone and grid-connected power-supply modes," IET Power Electronics, vol. 6, no. 4, pp. 752-762, 2013.

[18] O. Diouri, F. Errahimi, and N. Es-Sbai, "Regulation of the output voltage of an inverter in case of load variation," IOP Conference Series: Materials Science and Engineering, vol. 353, article 012021, 2018.

[19] L. Schirone, F. Celani, and M. Macellari, "Discrete-time control for DC-AC converters based on sliding mode design," IET Power Electronics, vol. 5, no. 6, pp. 833-840, 2012.

[20] D.-C. Lee and G.-M. Lee, "Linear control of inverter output voltage in overmodulation," IEEE Transactions on Industrial Electronics, vol. 44, no. 4, pp. 590-592, 1997.

[21] I. S. Kim and M. J. Youn, "Variable-structure observer for solar-array current estimation in a photovoltaic powergeneration system," IEE Proceedings - Electric Power Applications, vol. 152, no. 4, pp. 953-959, 2005.
[22] A. Hasanzadeh, C. S. Edrington, H. Mokhtari, B. Maghsoudlou, and F. Fleming, "Multi-loop linear resonant voltage source inverter controller design for distorted loads using the linear quadratic regulator method," IET Power Electronics, vol. 5, no. 6, pp. 841-851, 2012.

[23] H. Komurcugil, "Steady-state analysis and passivity-based control of single-phase PWM current-source inverters," IEEE Transactions on Industrial Electronics, vol. 57, no. 3, pp. 1026-1030, 2010.

[24] A. K. Zadeh, L. I. Kashkooli, and S. A. Mirzaee, "Designing a power inverter and comparing back-stepping, sliding-mode and fuzzy controllers for a single-phase inverter in an emergency power supply," Ciência e Natura, vol. 37, pp. 175-181, 2015.

[25] E. Kolbasi and M. Seker, "Nonlinear robust backstepping control method approach for single phase inverter," in 2016 21st International Conference on Methods and Models in Automation and Robotics (MMAR), pp. 954-958, Miedzyzdroje, Poland, 2016.

[26] Z. Ji, W. Wu, Y. Feng, and G. Zhang, "Constructing the Lyapunov function through solving positive dimensional polynomial system," Journal of Applied Mathematics, vol. 2013, Article ID 859578, 5 pages, 2013.

[27] A. Vyas Ojha and A. Khandelwal, "Control of non-linear system using backstepping," International Journal of Research in Engineering and Technology, vol. 4, no. 5, pp. 606-610, 2015.

[28] L. Ammeh, H. E. Fadil, A. Yahya, K. Ouhaddach, F. Giri, and T. Ahmed-Ali, "A nonlinear backstepping controller for inverters used in microgrids," IFAC-PapersOnLine, vol. 50, no. 1, pp. 7032-7037, 2017.

[29] F.-S. Kang, S.-J. Park, S. E. Cho, C.-U. Kim, and T. Ise, "Multilevel PWM inverters suitable for the use of stand-alone photovoltaic power systems," IEEE Transactions on Energy Conversion, vol. 20, no. 4, pp. 906-915, 2005.

[30] H. A. Sher, A. A. Rizvi, K. E. Addoweesh, and K. Al-Haddad, "A single-stage stand-alone photovoltaic energy system with high tracking efficiency," IEEE Transactions on Sustainable Energy, vol. 8, no. 2, pp. 755-762, 2017.

[31] P. K. Peter and V. Agarwal, "Photovoltaic module-integrated stand-alone single-stage switched capacitor inverter with maximum power point tracking," IEEE Transactions on Power Electronics, vol. 32, no. 5, pp. 3571-3584, 2017.

[32] S. K. Hosseini, M. Mehrasa, S. Taheri, M. Rezanejad, E. Pouresmaeil, and J. P. S. Catalao, "A control technique for operation of single-phase converters in stand-alone operating mode," in 2016 IEEE Electrical Power and Energy Conference (EPEC), pp. 1-6, Ottawa, ON, Canada, 2016.

[33] M. Mehrasa, M. Rezanejhad, E. Pouresmaeil, J. P. S. Catalao, and S. Zabihi, "Analysis and control of single-phase converters for integration of small-scaled renewable energy sources into the power grid," in 2016 7th Power Electronics and Drive Systems Technologies Conference (PEDSTC), pp. 384-389, Tehran, Iran, 2016.

[34] O. Diouri, N. Es-Sbai, F. Errahimi, A. Gaga, and C. Alaoui, "Control of single phase inverter using back-stepping in stand-alone mode," in 2019 International Conference on Wireless Technologies, Embedded and Intelligent Systems (WITS), pp. 1-6, Fez, Morocco, 2019. 

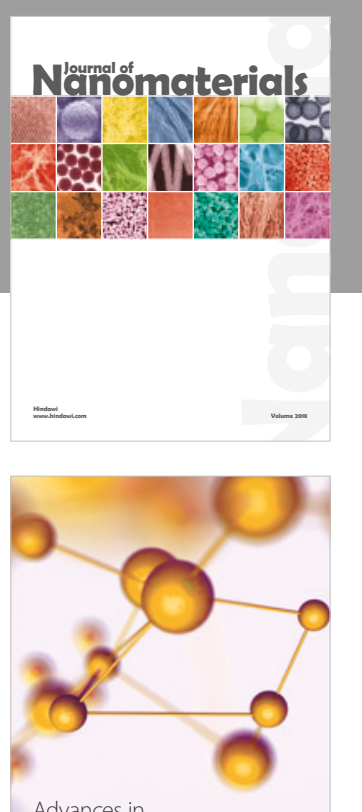

Physical Chemistry
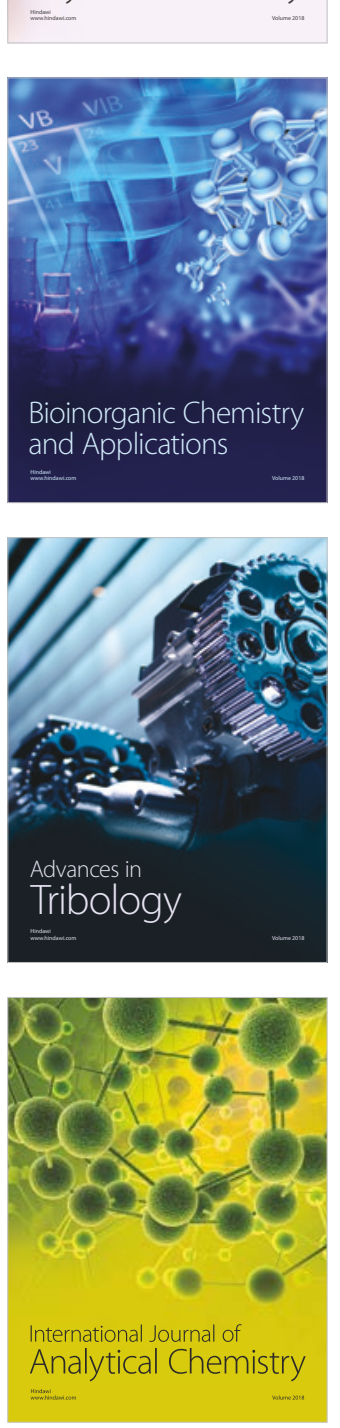

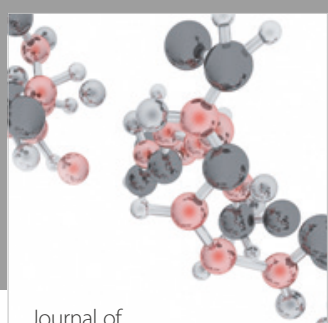

Analytical Methods

in Chemistry

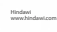

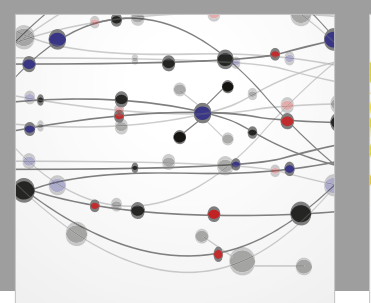

The Scientific World Journal

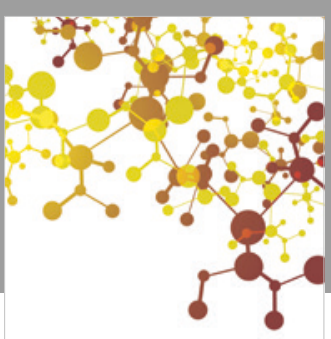

Journal of

Applied Chemistry
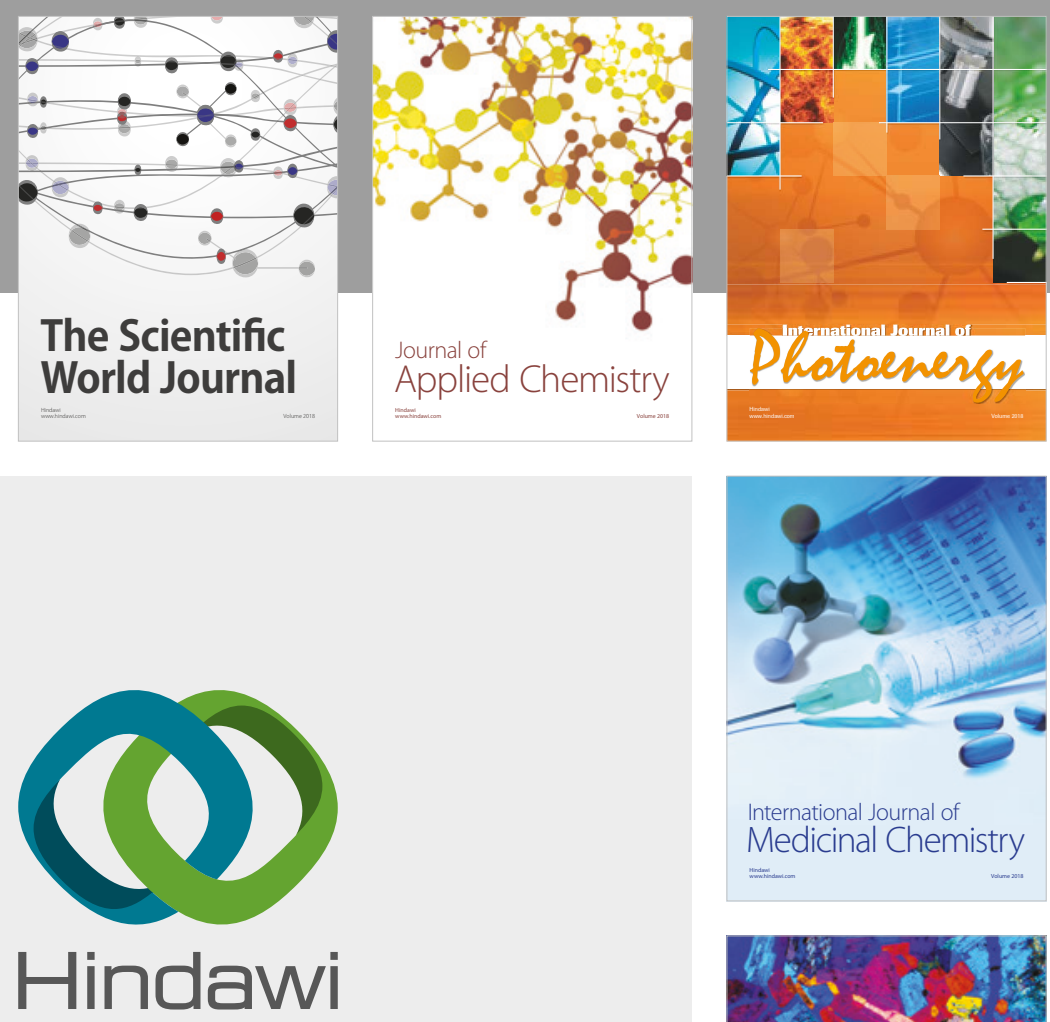

Submit your manuscripts at

www.hindawi.com
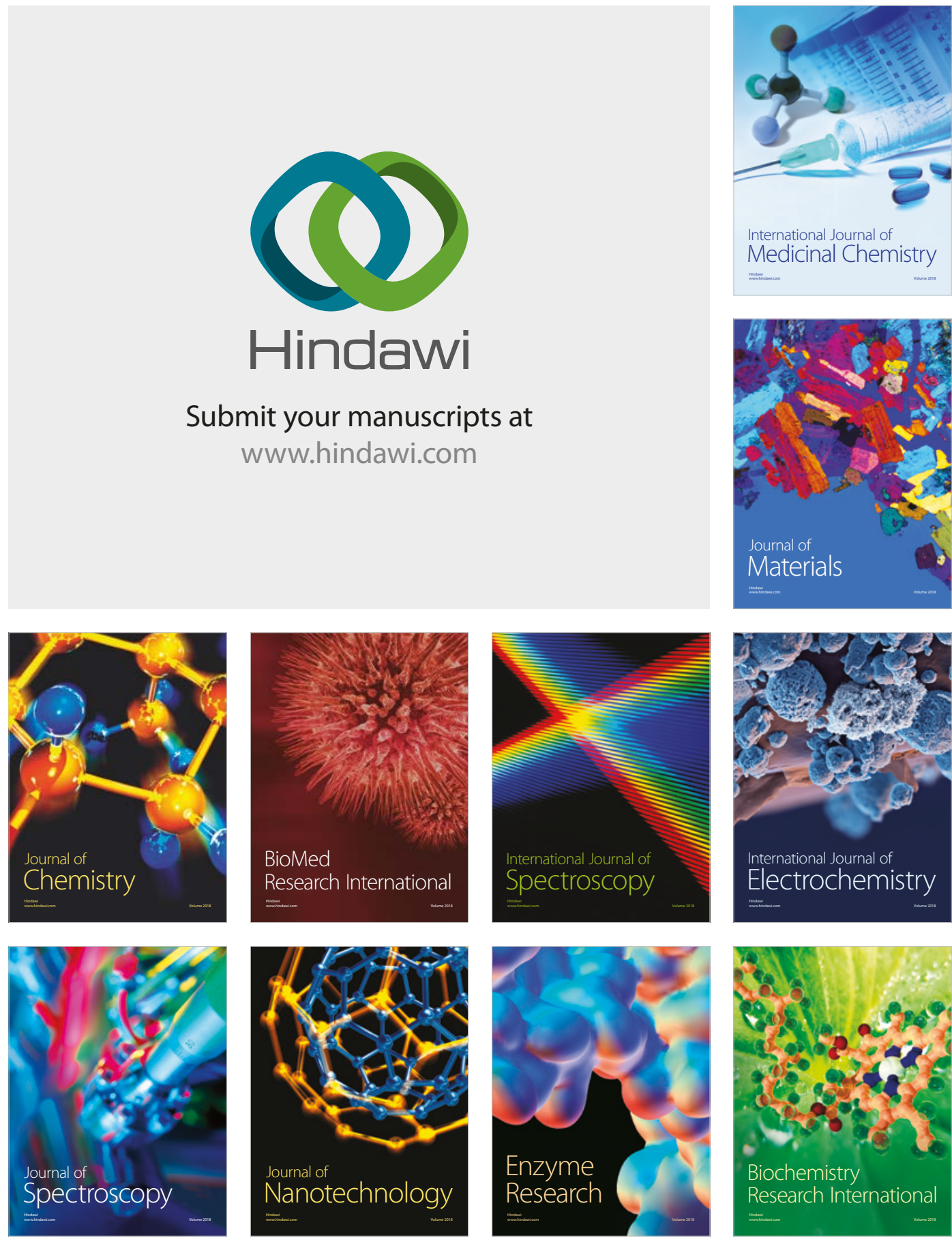
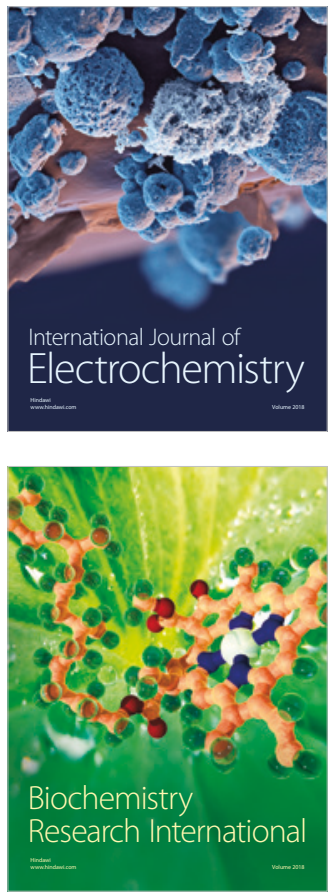